\title{
Genome analysis of Pseudomonas sp. OF001 and Rubrivivax sp. A210 suggests multicopper oxidases catalyze manganese oxidation required for cylindrospermopsin transformation
}

Erika Berenice Martínez-Ruiz ${ }^{1 *}$, Myriel Cooper ${ }^{1 *}$ D, Jimena Barrero-Canosa ${ }^{1}$, Mindia A. S. Haryono², Irina Bessarab², Rohan B. H. Williams ${ }^{2}$ and Ulrich Szewzyk ${ }^{1}$

\begin{abstract}
Background: Cylindrospermopsin is a highly persistent cyanobacterial secondary metabolite toxic to humans and other living organisms. Strain OF001 and A210 are manganese-oxidizing bacteria (MOB) able to transform cylindrospermopsin during the oxidation of $\mathrm{Mn}^{2+}$. So far, the enzymes involved in manganese oxidation in strain OF001 and A210 are unknown. Therefore, we analyze the genomes of two cylindrospermopsin-transforming MOB, Pseudomonas sp. OF001 and Rubrivivax sp. A210, to identify enzymes that could catalyze the oxidation of $\mathrm{Mn}^{2+}$. We also investigated specific metabolic features related to pollutant degradation and explored the metabolic potential of these two MOB with respect to the role they may play in biotechnological applications and/or in the environment.

Results: Strain OF001 encodes two multicopper oxidases and one haem peroxidase potentially involved in $\mathrm{Mn}^{2+}$ oxidation, with a high similarity to manganese-oxidizing enzymes described for Pseudomonas putida GB-1 (80, 83 and $42 \%$ respectively). Strain A210 encodes one multicopper oxidase potentially involved in $\mathrm{Mn}^{2+}$ oxidation, with a high similarity (59\%) to the manganese-oxidizing multicopper oxidase in Leptothrix discophora SS-1. Strain OF001 and A210 have genes that might confer them the ability to remove aromatic compounds via the catechol metaand ortho-cleavage pathway, respectively. Based on the genomic content, both strains may grow over a wide range of $\mathrm{O}_{2}$ concentrations, including microaerophilic conditions, fix nitrogen, and reduce nitrate and sulfate in an assimilatory fashion. Moreover, the strain A210 encodes genes which may convey the ability to reduce nitrate in a dissimilatory manner, and fix carbon via the Calvin cycle. Both MOB encode CRISPR-Cas systems, several predicted genomic islands, and phage proteins, which likely contribute to their genome plasticity.
\end{abstract}

\footnotetext{
* Correspondence: erika.b.martinezruiz@campus.tu-berlin.de;

myriel.cooper@tu-berlin.de

${ }^{1}$ Chair of Environmental Microbiology, Technische Universität Berlin, Institute of Environmental Technology, Straße des 17. Juni 135, 10623 Berlin, Germany Full list of author information is available at the end of the article
}

(c) The Author(s). 2021 Open Access This article is licensed under a Creative Commons Attribution 4.0 International License, which permits use, sharing, adaptation, distribution and reproduction in any medium or format, as long as you give appropriate credit to the original author(s) and the source, provide a link to the Creative Commons licence, and indicate if changes were made. The images or other third party material in this article are included in the article's Creative Commons licence, unless indicated otherwise in a credit line to the material. If material is not included in the article's Creative Commons licence and your intended use is not permitted by statutory regulation or exceeds the permitted use, you will need to obtain permission directly from the copyright holder. To view a copy of this licence, visit http://creativecommons.org/licenses/by/4.0/ The Creative Commons Public Domain Dedication waiver (http://creativecommons.org/publicdomain/zero/1.0/) applies to the data made available in this article, unless otherwise stated in a credit line to the data. 
Conclusions: The genomes of Pseudomonas sp. OF001 and Rubrivivax sp. A210 encode sequences with high similarity to already described MCOs which may catalyze manganese oxidation required for cylindrospermopsin transformation. Furthermore, the analysis of the general metabolism of two MOB strains may contribute to a better understanding of the niches of cylindrospermopsin-removing $M O B$ in natural habitats and their implementation in biotechnological applications to treat water.

Keywords: Metabolic potential, Manganese-oxidizing bacteria, Biotransformation, Cyanotoxins

\section{Background}

Cylindrospermopsin (CYN) is a secondary metabolite produced by several cyanobacteria, toxic for humans and other living organisms [1]. The two bacterial strains OF001 and A210 transform the cyanotoxin CYN during the oxidation of $\mathrm{Mn}^{2+}[2,3]$. Strain OF001 belongs to the gammaproteobacteria and was isolated from the effluent of an experimental fixed-bed biofilm reactor established for the removal of recalcitrant substances from wastewater. Strain A210 belongs to the betaproteobacteria and was isolated from an iron manganesedepositing biofilm in a freshwater pond in the Lower Oder Valley National Park, Germany.

The removal of CYN by both strains required the active oxidation of $\mathrm{MnCO}_{3}$ whereas no or low CYN removal was observed with $\mathrm{MnSO}_{4}$ or in setups without manganese. Sterile biogenic oxides formed by the strains did not show any influence on CYN removal, highlighting the importance of the active manganese oxidation. Both strains are able to remove $100 \%$ of CYN at the highest rates reported for biological CYN removal so far $[2,3]$. Furthermore, analysis of CYN transformation products revealed that the same seven transformation products were formed by both strains corroborating the important role of manganese oxidation. However, strain OF001 and A210 showed important differences. Pseudomonas sp. strain OF001 degraded CYN within 3 days. Whereas strain A210 degraded CYN within 14 to 28 days when cultivated under the same conditions. Moreover, strain OF001 required yeast extract as additional carbon source for the removal of CYN. In contrast, strain A210 was able to transform CYN in mineral media [2].

So far, little is known about biological CYN removal [2-6]. Even though several bacterial strains have been reported to remove CYN, to date, no enzymes or defined metabolic pathway for the transformation of CYN have been identified [7, 8]. Moreover, for biological CYN removal, no transformation products have been identified except for CYN transformed by MOB [3].

MOB are present in terrestrial [9], marine and freshwater environments [10-13], but they also occur in drinking water systems and reactors aiming at the removal of manganese and other pollutants [13-16]. MOB belong to diverse phylogenetic lineages with a broad physiological diversity (e.g. autotrophs and mixotrophs) $[10,17,18]$. Through the oxidation of $\mathrm{Mn}^{2+}$, MOB form water-insoluble biogenic manganese oxides, which are one of the strongest natural oxidants [17, 19]. Biogenic manganese oxides often interact with other compounds and thus play an important role in the biogeochemical cycle of manganese and other elements [17, 18, 20, 21].

The physiological role of manganese oxidation is not fully understood. Manganese oxidation was proposed to provide energy to support the growth of bacteria. However, no conclusive results were shown [22]. Other proposed functions are the protection against the toxicity of organic compounds, and reactive oxygen species [23, 24], the breakdown of organic matter into utilizable substrates $[25,26]$, and the use as a carbon reservoir [27]. Nevertheless, the precise physiological role of manganese oxidation remains unknown [18]. Different manganese oxidation mechanisms have been described including non-enzymatic pathways based on a $\mathrm{pH}$ increase, the oxidation through superoxide production, or an anaerobically photo-driven reaction; and enzymatic reactions generally associated to the activity of multicopper oxidases (MCO) and haem peroxidases [11, 18, 28].

Besides CYN, MOB transform different organic and inorganic pollutants, including diclofenac, benzotriazole, $17 \alpha$-ethinylestradiol, bisphenol A, As(III), and $\mathrm{Sb}$ (III) [2, 3, 29-34]. The mechanism of pollutant transformation was proposed to be based on unspecific oxidation by reactive manganese $\mathrm{Mn}^{3+} / \mathrm{Mn}^{4+}$ species that are formed through the oxidation of $\mathrm{Mn}^{2+}$ [29]. For CYN transformation, a similar mechanism was assumed based on the requirement of active $\mathrm{Mn}^{2+}$ oxidation for efficient CYN removal and the formation of the same transformation products among all tested $\mathrm{MOB}$, including strain OF001 and A210 [3]. Thus, it is suggested that MOB act as suppliers of biogenic oxides that indirect oxidize the pollutants. However, the intrinsic capacity of MOB to remove organic compounds has not been deeply investigated [18].

The whole genome sequences of some MOB have been analysed previously to gain a better insight into the mechanism of manganese oxidation [35, 36]. However, so far, no reported pollutant-removing $\mathrm{MOB}$ strains were analyzed on a genomic level. Besides, for strain 
OF001 and A210, information about the metabolic potential, including also about genes potentially involved in manganese oxidation, was missing. The genomic analysis of strain OF001 and strain A210 might allow to identify enzymes potentially involved in the oxidation of manganese based on the comparison with manganese oxidizing enzymes reported to date. Furthermore, metabolic differences between the two MOB strains became evident during cultivation experiments in presence of CYN [2], and further dissimilarities could be assumed. Such metabolic differences could be relevant for the application of the strains for the removal of pollutants from water in technical systems including but not limited to wastewater or drinking water treatment plants, and for the understanding of the niche they may occupy in natural environments.

Therefore, in this study, we analysed the draft genomes of the MOB strains OF001 and A210, both of which are able to transform CYN during oxidation of $\mathrm{MnCO}_{3}$. We aim to provide further insight into i) manganese oxidation mechanism, ii) other metabolic pathways relevant for pollutant removal, iii) energy harvesting processes such as respiration, iv) their metabolic potential in comparison with their closest described phylogenetic relatives, and v) genome plasticity related to horizontal gene transfer mechanisms.

\section{Results and discussion}

\section{General genome features}

Genome quality estimation determined with CheckM showed that both genomes are of high quality (>90\% completeness and $<5 \%$ contamination). Genomes of strains OF001 and A210 have a completeness of 99.59 and $99.38 \%$, respectively, with a contamination level of 2.12 and $0.35 \%$.

The genome sequence of strain OF001 contains 4,476, $686 \mathrm{bp}$ in 65 contigs with a N50 contig length of 147, $742 \mathrm{bp}$, and a GC content of $68.01 \%$. The genome of strain OF001 encodes 4845 genes of which 4720 are protein coding sequences (CDS). Furthermore, one 16S, one 23S, and six 5S rRNA genes were identified in the genome of OF001, as well as, sixty-seven tRNA genes that enable recognition of codons for all 20 amino acids.

The genome sequence of strain A210 contains 5,371, 534 bp in 72 contigs with a N50 contig length of 327, $374 \mathrm{bp}$, and a GC content of $69.54 \%$. The genome of strain A210 encodes 5184 genes from which 5112 are CDS. In addition, one 5S-23S-16S rRNA operon, and 52 tRNA genes were identified in the genome of strain A210. Genome quality estimation and general genomic features are summarized in Table 1.

Genome Taxonomy Database tool kit (GTDB-tk) was used to classify the bacterial genomes. GTDB-tk analysis classified strain OF001 as a member of the

Table 1 Genomic features of strains OF001 and A210

\begin{tabular}{|c|c|c|}
\hline & OF001 & A210 \\
\hline N50 & 147,742 & 327,374 \\
\hline Number of contigs & 65 & 72 \\
\hline CheckM completeness & $99.59 \%$ & $99.38 \%$ \\
\hline CheckM contamination & $2.12 \%$ & $0.35 \%$ \\
\hline Complete genome size (bp) & $4,476,686$ & $5,371,534$ \\
\hline Undetermined bases & 6400 & 7100 \\
\hline$\%$ GC & 68.01 & 69.54 \\
\hline$\%$ Protein coding density & 90.64 & 93.09 \\
\hline Pseudogene & 6 & 2 \\
\hline CDS & 4720 & 5112 \\
\hline \multicolumn{3}{|l|}{ Genes assigned to: } \\
\hline COG & $3436(72.70 \%)$ & $3798(74.27 \%)$ \\
\hline KEGG & $2490(52.7 \%)$ & $2632(51.5 \%)$ \\
\hline Hypothetical proteins / unknown function & $1327(28.08 \%)$ & $1492(29.17 \%)$ \\
\hline Fragment CDS & 6 & 2 \\
\hline tRNA & 67 & 52 \\
\hline rRNA & 8 & 3 \\
\hline misc_RNA & 43 & 14 \\
\hline tmRNA & 1 & 1 \\
\hline
\end{tabular}


Pseudomonas_K group. According to the GTDB (May, 2020) $P$. oryzae, P. sagittaria, $P$. linyingensis, and $P$. guangdongensis belong to the Pseudomonas_K group. The genus status of the strain OF001 in the Pseudomonas_ K group was supported by the genetic relatedness determined by whole-genome analysis and $16 \mathrm{~S}$ rRNA phylogeny (Additional file 1: Fig. S1).

To determine the species affiliation of Pseudomonas sp. OF001 average nucleotide identity (ANI), and tetranucleotide frequencies (TETRA) analysis were done. The analysis revealed highest similarity between strain OF001 and P. oryzae KCTC 32247 with an ANI based on BLAST (ANIb) value of $89.06 \%$, an ANI based on MUMmer (ANIm) value of $90.98 \%$, and a TETRA value of 0.998 (Fig. 1a). Organisms with an ANI value above 95\%, and a TETRA value above 0.99 are suggested to delineate the same species level [38-40]. TETRA values should be in agreement with ANI values to support the species assignation [39]. TETRA values of strain OF001 and the organisms of the Pseudomonas_K group were higher than 0.99, but ANI values were below the species limit. Together, the data suggest strain OF001 is a potential new species of the Pseudomonas_K group.

GTDB-tk analysis classified strain A210 as a member of the Rubrivivax genus. According to the GTDB database this genus belongs to the order Burkholderiales and has so far only three described species: $R$. benzoatilyticus, $R$. gelatinosus, and R. albus [41-43].

Based on the phylogenetic analysis using the whole 16S rRNA gene sequence (Additional file 1: Fig. S2a), strain A210 could not be classified at genus level. Organisms with high similarity to the $16 \mathrm{~S}$ rRNA gene sequence of strain A210 were mainly bacteria of the genera incertae sedis from the Comamonadaceae family (Aquabacterium, Ideonella, Leptothrix, Roseateles, Rubrivivax, Sphaerotilus). However, phylogenomic analysis of strain A210 done with TYGS platform affiliated A210 with organisms of the genus Rubrivivax (Additional file 1: Fig. S2b), supporting the results obtained with the GTDB-tk.

ANI, and TETRA analysis were done with the genome of A210 to analyze species affiliation. The analysis showed the highest similarity of Rubrivivax sp. A210 with $R$. benzoatilyticus JA2 with an ANIb value of $76.69 \%$, an ANIm value of $84.45 \%$, and a TETRA value of 0.913 (Fig. 1b). Thus suggesting, strain A210 is a potential new species of the genus Rubrivivax.

\section{Pan and core genome}

The pan-genome of the Pseudomonas_K group genomes comprised 20,296 genes belonging to 6805 Microscope gene Families (MICFAM) [44, 45]. The core-genome comprised 11,985 genes that correspond to $1957 \mathrm{MICF}$ $\mathrm{AM}$, and the variable-genome contained 8311 corresponding to 4848 MICFAM. The Pseudomonas sp. OF001 genome contains 1091 strain-specific genes from 1052 MICFAM that correspond to $24.08 \%$ strain-specific coding sequences. With this, strain OF001 contains the highest number of CDS from the Pseudomonas_K group genomes analyzed (Additional file 1: Fig. S3a). Among the strain-specific genes in OF001, we found genes related to mercury resistance, transport, and foreign DNA (see also section 2.5 Elements potentially acquired by horizontal gene transfer).

Pan- and core-genome size evolutions were estimated with the four available genomes of the Pseudomonas_K group and the genome of strain OF001. The curve of the pan-genome of strain OF001 and Pseudomonas_K group did not reach the plateau, suggesting that the pangenome of Pseudomonas_K group is open and the sequences of other genomes from this group might increase the gene pool of novel genes (Additional file 1: Fig. S4a). The plateau of the core-genome is reached
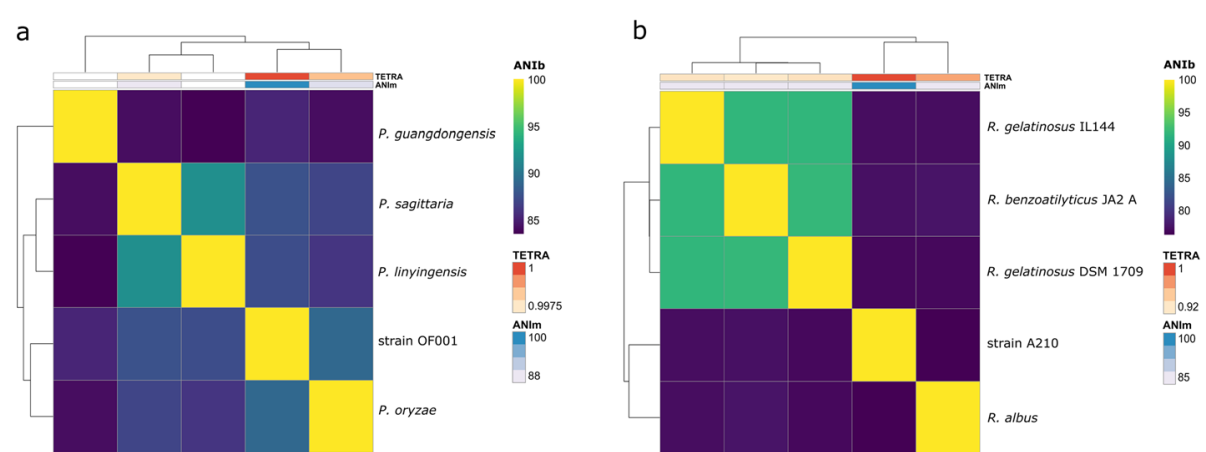

Fig. 1 Heatmap representing the degree of similarity of the MOB genomes. a Pseudomonas sp. OF001, and b Rubrivivax sp. A210. Heatmaps were derived from the average nucleotide identity (ANI) matrix based on BLAST (ANIb). Dendrogram directly reflects the degree of identity between genomes. ANIm: ANI based on MUMmer; TETRA: correlation indexes of the tetra-nucleotide frequencies; DDH $d_{4}$ : DDH calculated with the formula $d_{4}$, which is the non-logarithmic version of formula $d_{5}$ (used for the Fig. S1 and S2). Formula $d_{4}$ is highly recommended when using draft genomes to assure confident results [37] 
with the five genomes selected and is composed of approximately 2000 MICFAM (Additional file 1: Fig. S4b).

The pan-genome of Rubrivivax genomes comprised 23,140 genes belonging to 9974 MICFAM. The coregenome comprises 10,154 genes that correspond to 1629 MICFAM, and the variable-genome contains 12,986 genes corresponding to 8345 MICFAM. The Rubrivivax sp. A210 genome contains 2123 strain-specific genes from 2035 MICFAM that correspond to $42.98 \%$ strainspecific coding sequences (Additional file 1: Fig. S3b). Among the strain-specific genes in A210, we found genes related to transport like $\mathrm{ABC}$ transporters, and cytochromes (see also section 2.4.3 Aerobic respiration).

Pan- and core-genome size evolutions were estimated according to the genomes selected for the A210 analysis (Additional file 1: Fig. S4c-d). The core-genome plateau is apparently reached with the analyzed genomes and is composed of approximately 1600 MICFAM.

\section{Genes potentially involved in manganese oxidation}

In Pseudomonas sp. OF001, we detected three different homologues of manganese-oxidizing multicopper oxidases (MO-mco's) (OF001_u20185, OF001_u60094, and OF001_u90046). Gene name, accession number, locus tag in the evaluated genomes, E-value, and percent similarity of amino acid alignments are shown in Additional file 1: Table S1. All three MO-mco's homologues of strain OF001 belong to the homologous cupredoxin superfamily (IPR008972), according to the InterPro- based analysis. The amino acid sequences encoded by OF001_u20185 and OF001_u60094 exhibit the four characteristic motifs found in multicopper oxidases, in the same order and in a similar position as observed in McoA and MnxG from P. putida GB-1 (Fig. 2a, b). In addition, MO-mco's homologues OF001_u20185 and OF001_u60094, showed the highest similarity to the $\mathrm{Mn}^{2+}$ oxidases $m n x G(80 \%)$ and $m c o A$ (83\%) from $P$. putida GB-1 [47], whereas OF001_u90046 showed the highest similarity to moxA (51\%) from Pedomicrobium sp. ACM 3067 [48]. According to the InterPro-based analysis, all three MO-mco's contain non-cytoplasmic domain regions of membrane-bound proteins that cover more than $94 \%$ of the whole protein sequence. These regions are predicted to be outside the membrane in the extracellular region. Moreover, OF001_u90046 and OF001_u60094 contain transmembrane helixes. The presence of non-cytoplasmic and transmembrane domains suggests that these enzymes are loosely bound to the outer membrane, which is in agreement with the localization of MO-mco's in other MOB [47, 49, 50]. Functional domains of the proteins and the ontology classification are shown in Additional file 1: Table S2.

OF001_u60094 in Pseudomonas sp. OF001 is located in a predicted operon similar to $m n x G$ in P. putida GB1 [51]. The operon is composed out of five additional genes with high similarity to those located in the $m n x G$ operon of P. putida GB-1, (63-76\% according to blastp analysis, Fig. 2c). Expression of the MO-mco's in $P$.
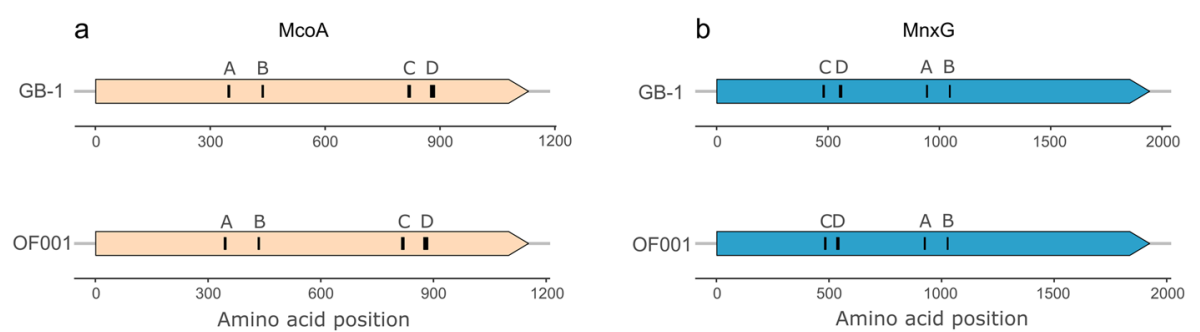

C

d
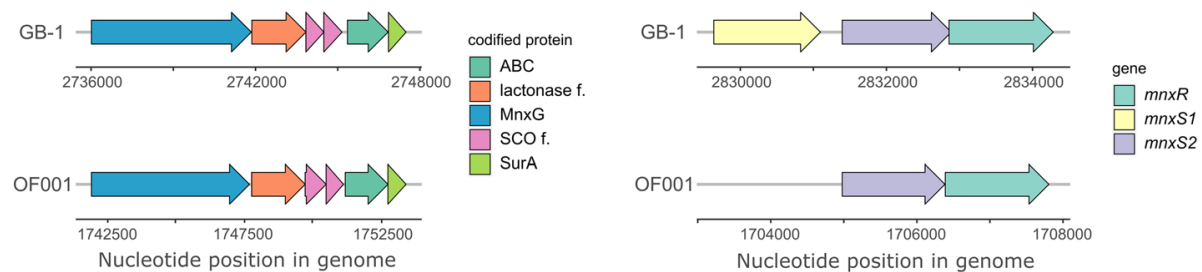

Fig. 2 Genetic organization of regulatory system and MO-mco's in P. putida GB-1 and Pseudomonas sp. OF001. a McoA protein of strain GB-1, and the putative homolog found in strain OF001, b MnxG protein of strain GB-1, and the putative homolog found in strain OF001, $\mathbf{c}$ predicted operon organization in which $m n x G(\mathrm{MO}-\mathrm{mco})$ is found in strain GB-1, and putative homologues found in a predicted operon in strain OF001, and $\mathbf{d}$ regulatory system for $\mathrm{Mn}^{2+}$ oxidation of strain GB-1, and putative homologues found in strain OF001. Capital letters (A-D) in a), and $\mathbf{b}$ ) represent the multicopper oxidase motifs [46]. $m n x R$ : response regulator; $m n x S 1$ and $m n x S 2$ : sensor histidine kinases; $A B C$ : $A B C$ transporter; lactonase f: beta-propeller fold lactonase family protein; mnxG: MO-mco, SCO f. SCO family protein; SurA: SurA N-terminal domain-containing protein, McoA: MO-mco, MnxG: MO-mco 
putida GB-1 is regulated by a two-component pathway, $m n x S 1 / m n x S 2 / m n x R$ [51]. In the genome of strain OF001, we found putative homologues to the $m n x S 2$ histidine kinase, and to the $m n x R$ regulator, arranged in a similar operon structure as in P. putida GB-1 (Fig. 2d) [51]. Our results suggest that the regulation of the MOmco's of strain OF001 follows a similar regulation to the one observed in P. putida GB-1.

Furthermore, two homologues of manganese-oxidizing haem peroxidases (MO-hpox's) (OF001_u100035, and OF001_u220048) were identified in strain OF001. The putative MO-hpox homologue OF001_u100035 showed the highest similarity with the $\mathrm{Mn}^{2+}$ oxidase mopA of $P$. putida GB-1 (42\%). Together with the MO-hpox of $A$. manganoxydans SI85-9A1, they belong to the haem peroxidase superfamily (IPR010255). The MO-hpox homologue OF001_u220048, showed highest similarity to mopA of Erythrobacter sp. SD-21 (38\%) and neither of the two belong to the haem peroxidase superfamily (Additional file 1: Table S2). No cytoplasmic or noncytoplasmic domains could be identified for the putative MO-hpox's homologues of strain OF001. Therefore, we evaluated the probable subcellular localization with LocTree3 [52]. According to this analysis, both putative MO-hpox's of OF001 are likely secreted to the media (accuracy percentage $88 \%$ ), similar as previously described for several MO-hpox's of other MOB [47-50, 53, 54].

In the genome of Rubrivivax sp. A210, five MO-mco's homologues were identified (RA210_u420004, RA210_ u30250, RA210_u110082, RA210_u10102, and RA210_ u100111) (Additional file 1: Table S1). Two MO-hpox's homologues (RA210_u10091, and RA210_u140033) were identified, but were discarded for further analysis due to very low coverage of the query sequences (Additional file 1: Table S1).

All MO-mco's homologues of strain A210 belong to the homologous cupredoxin superfamily (IPR008972), according to the InterPro-based analysis. They contain non-cytoplasmic domains which cover more than $84 \%$ of the whole protein sequence, and possess either a transmembrane domain or a transmembrane helix, except for RA210_u420004. This suggests that these enzymes are loosely bound to the outer membranes, similar as previously reported for other MO-mco's [47, 49, 50]. RA210_ u30250 shows highest similarity (59\%) to the mofA gene of $L$. discophora SS-1 [49]. In addition, the amino acid sequence of RA210_u30250 encodes the four characteristic motifs found in multicopper oxidases in the same order and in a similar position than those found in MofA from L. discophora SS-1 (Fig. 3a). In addition, it is located in a predicted operon similar to mofA in L. discophora SS-1 (Fig. 3b). The mof operon in L. discophora SS- 1 is composed out of mofA, mofB and mofC [55]. The putative mof operon in strain A210 encodes five genes, including the putative mofA homologue, and two genes with high similarity to mofB (68\%) and mofC (60\%), together with a putative metallochaperon, and an exported protein of unknown function (RA210_u30246 - RA210_ u30250).

In spite of the low homology between MO-mco's from different organisms, we attempted to gain further evidence for the $\mathrm{Mn}^{2+}$ oxidation activity of the suggested multicopper oxidases by using a phylogenetic approach. For this purpose, a phylogenetic tree was constructed with sequences of MO-mco and non-MO-mco retrieved form the NCBI database excluding the newly identified putative MO-mco homologues (Additional file 1: Table S3), to discard the possibility that the new sequences were the main factor driving the topology of the tree (Additional file 1: Fig. S5). Subsequently, the putative MO-mco homologues of the strains OF001 and A210 were added. Phylogenetic analysis revealed one cluster of all MO-mco sequences and one cluster of non-MO-mco (Fig. 4). The only identified outlier was moxA from Pedomicrobium sp. ACM 3067, a reported MO-mco, affiliated with the non-MO-mco. Possibly, this is due to an uncertain assignation as suggested previously by
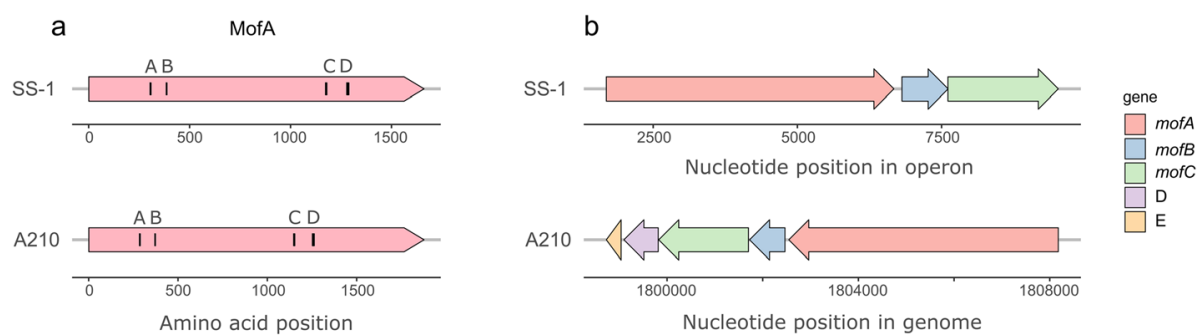

Fig. 3 Genetic organization of the MO-mco in L. discophora SS-1 and Rubrivivax sp. A210. a MofA protein of strain SS-1, and the putative homolog found in strain A210, and $\mathbf{b}$ predicted operon organization in which mofA (MO-mco) is found in strain SS-1, and the putative homologues found in a predicted operon in strain A210. Capital letters (A-D) in a) represent the multicopper oxidase motifs [46]. mofA: MO-mco; mofB: macrophage infectivity potentiator (mip); mofC: Cytochrome c domain-containing protein. Note that in a the operon in strain SS-1 is represented based on the total length of the operon because the genome has not been sequenced. Capital letters in $\mathbf{b}$ are the other two proteins predicted within the operon of strain A210, D: copper metallochaperone, and E: protein of unknown function 


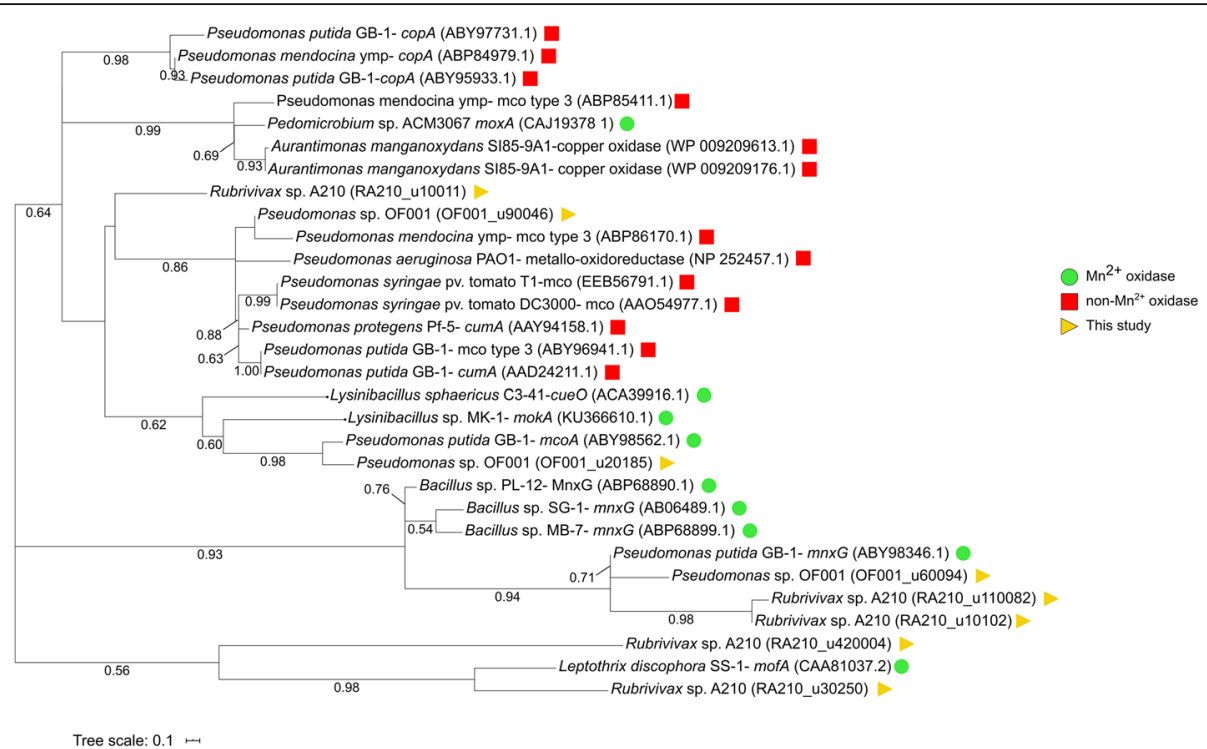

Fig. 4 Maximum Likelihood phylogenetic tree based on multicopper oxidase sequences with and without reported $\mathrm{Mn}^{2+}$ oxidation activity. Numbers in the branches represent bootstrap values. Scale bar represents sequence divergence

Anderson et al. (2009). In contrast to OF001_u20185, OF001_u60094, and RA210_u30250, the proteins encoded by OF001_u90046, and RA210_u100111 did not cluster with the MO-mco (Fig. 4). This result suggests that the two annotated multicopper oxidases OF0011_u90046 and RA210_u100111 in Pseudomonas sp. OF001 and Rubrivivax sp. A210, respectively, do not possess the $\mathrm{Mn}^{2+}$ oxidation activity. Collectively, the data suggest that the best candidates for $\mathrm{Mn}^{2+}$ oxidation are MO-mco OF001_u20185, OF001_u60094, and MOhpox OF001_u100035 in strain OF001 and MO-mco RA210_u30250 in strain A210.

Our results indicate that both MOB strains, OF001 and A210, oxidize manganese through enzyme-mediated mechanisms. In spite of the evidences found based on the genomic analysis, further experiments are required to determine which enzymes are involved in the oxidation of $\mathrm{Mn}^{2+}$ in Pseudomonas sp. OF001 and Rubrivivax sp. A210.

\section{General metabolism \\ Organic carbon metabolism}

Pseudomonas sp. OF001 and Rubrivivax sp. A210 possess all genes necessary for commonly found central carbohydrate metabolism in aerobic organism including glycolysis (Embden-Meyerhof-Parnas), gluconeogenesis, tricarboxylic acid cycle (Krebs cycle), and the nonoxidative branch of the pentose phosphate pathway, to support basic growth. In both $\mathrm{MOB}$, genes involved in the oxidative branch of the pentose phosphate pathway were incomplete which is in accordance with its absence in many aerobic and thermophilic organisms [56].

\section{$\mathrm{CO}_{2}$ fixation}

Pseudomonas sp. OF001 possesses several genes encoding enzymes related to $\mathrm{CO}_{2}$ fixation via the Calvin cycle, however the key enzyme D-ribulose-1,5-bisphosphate carboxylase/oxygenase (RuBisCO) is missing (Additional file 1: Table S4). This is in accordance with our previous study which demonstrated the growth of strain OF001 only in presence of an organic carbon source [2].

In contrast, Rubrivivax sp. A210 has the complete repertoire of genes required for $\mathrm{CO}_{2}$ fixation via the Calvin cycle, including the $\mathrm{RuBisCO}$, which is supported by previous studies of our group showing that A210 was able to grow in mineral media [2]. The $c b b$ operon in strain A210 has all genes predicted to be encoded together with the RuBisCO small ( $c b x S P)$ and large $(c b b L)$ subunits ( $g p x, c b b Y P, p r k B, f b p, c b x X C)$. The presence of genes coding for enzymes of the Calvin cycle in strain A210 is in accordance with their detection in the three described species of the Rubrivivax genus $R$. albus [42], R. gelatinosus [43] and R. benzoatilyticus [41].

\section{Aerobic respiration}

All genes for oxidative phosphorylation and aerobic respiration were present in Pseudomonas sp. OF001. Among them, twenty genes annotated as cytochromes, including $14 c$-type, $5 b$-type, and $1 d$-type cytochromes were found (Additional file 1: Table S5). Also, several predicted terminal oxidases are present including cytochrome $b d$-type quinol oxidase, cytochrome $c$ oxidases, and $c b b_{3}$-type cytochrome $c$ oxidases.

$c b b_{3}$-type cytochrome $c$ oxidases in the genome of strain OF001 are predicted to be organized in two 
operons, one operon containing $c b b P$ and $c b b Q O N$ genes, similar as reported for other bacteria [57-60], and one operon containing a copy of $c b b P O$ and a gene of unknown function. Next to the $c b b P Q O N$ operon, a predicted operon with three (ccoSIG) genes encoding the enzymes responsible of the assembly of $c b b_{3}$-type cytochrome $c$ oxidases was observed [61]. The $c c o H$ assembly factor for the $c b b_{3}$-type cytochrome oxidase is missing in strain OF001, suggesting that it follows a $c c o H$-independent assembly mechanism, similar as described for $H$. pylori, and $R$. gelatinosus (Durand et al. 2018).

Likewise, all genes for oxidative phosphorylation and aerobic respiration were found in Rubrivivax sp. A210. Thirty-nine genes were annotated as cytochromes, including thirty $c$-type, and nine $b$-type cytochromes. Predicted terminal oxidases are present, including cytochrome $c$ oxidases and $c b b_{3}$-type cytochrome $c$ oxidases (Additional file 1: Table S5). cbb3-type cytochrome $c$ oxidases and the enzymes responsible of their assembly in the genome of strain A210 are predicted to be organized in a single operon ccoISNOQPG. Similar as for OF001, the $c c o H$ assembly factor for the $c b b_{3}$-type cytochrome oxidase is missing in strain A210, which suggest that it also follows a $c c o H$-independent assembly mechanism likewise to strain OF001.

The presence of diverse cytochrome oxidases, with high $\mathrm{O}_{2}$ affinity, rather than only cytochrome $c$ oxidases, indicate the potential of strain OF001 and A210 to grow under a wide range of $\mathrm{O}_{2}$ concentrations.

\section{Nitrogen metabolism}

Pseudomonas sp. OF001 possesses genes predicted to participate in ammonium uptake, including specific transporters like $a m t B$ and genes involved in the regulation of the process such as $g \ln A, g \ln L$, and $g \ln K$ [62-67]. The genes are predicted to be arranged within different operons, with $g \ln A$ as a single regulated gene, located immediately downstream from the operon encoding $g \ln G$ and $g \ln L$ (Additional file 1: Table S4).

In addition, the genome of Pseudomonas sp. OF001 encodes the genes nifDKH, implicated in nitrogen fixation. Nitrogenase genes in strain OF001 are not predicted to form an operon, but cluster together in the genome. The detection of the nifDKH genes is in accordance with their detection in the genomes of the two taxonomically closest organisms to OF001, P. linyingensis [68] and P. sagittaria [69].

Furthermore, strain OF001 encodes genes related with assimilatory nitrate reduction, including nitrate transport, the ammonium-forming nitrite reductase small subunit nasD, and the nitrate reductase nas $A$ [70-73]. Strain OF001 also possesses two nitrite reductases, one in a predicted operon together with the nitrate reductase nas $A$, and the other as an independent regulated gene (Additional file 1: Table S4). Genes involved in dissimilatory nitrate reduction were missing. This is in agreement with the absence of genes involved in dissimilatory nitrate reduction in the closest related Pseudomonas_K group.

Similar to strain OF001, the genome of Rubrivivax sp. A210 encodes genes predicted to participate in ammonium uptake in five predicted operons, including specific transporters like $a m t B$ and genes involved in the regulation of the process such as $g \ln A, g \ln L$, and $g \ln K$ [62-67] (Additional file 1: Table S4). However, in contrast to strain OF001, the $g \ln B$ gene is encoded in the genome of strain A210. GlnB is a PII signal transcription protein, homologue to GlnK [74]. Both are key for the metabolic regulation of ammonium uptake. The presence of the $g \ln K$ and $g \ln B$ genes in Rubrivivax sp. A210 suggests that ammonium uptake in strain A210 follows a similar regulation as described for Escherichia coli [64, 75]. GlnB found in Proteobacteria is commonly associated with glutamine synthetase genes [76], and likewise, the $g \ln B$ gene of strain A210 is located in an operon structure next to the glutamine synthetase nadE.

The genes nifDKH, implicated in nitrogen fixation, are encoded in the genome of Rubrivivax sp. A210 similarly as observed for all three known Rubrivivax species [4143]. The nifDKH genes are located in a predicted operon structure together with a putative ferredoxin and a conserved protein of unknown function. Ferredoxin may mediate nitrogenase activity when ammonium is available for uptake [77-80].

Moreover, strain A210 encodes genes related with assimilatory nitrate reduction, including nitrate transport, the ammonium-forming nitrite reductase small subunit nirB, and the nitrate reductase nas $A$ [70-73].

In contrast to strain OF001, in the genome of strain A210 genes related with dissimilatory nitrate reduction were detected, including nitrate reductase narGHI, and nitrite reductase nirBD. Noteworthy, in the three described species of the Rubrivivax genus [41-43], genes coding for enzymes related to dissimilatory nitrate reduction were not detected.The enzymes related with the dissimilatory and assimilatory nitrate reduction are organized in two predicted operons.

The genomic data indicate that both MOB strains have the ability to assimilate ammonium. In addition, it seems likely that OF001 can use nitrate in an assimilatory but not dissimilatory pathway. In contrary, the genomic data suggest that Rubrivivax sp. A210 has not only the genomic potential to assimilate nitrate, but also to perform anaerobic respiration using nitrate as final electron acceptor. This characteristic may confer a higher flexibility to strain A210, compared to OF001, to adapt to changing conditions in technical and natural environments. 


\section{Sulfur metabolism}

Pseudomonas sp. OF001 harbours all genes required for assimilatory sulfate reduction, which are organised in several predicted operons, and some as single regulated genes (Additional file 1: Table S4). Strain OF001 also possesses different sulfate transporters including $A B C$ type UWA [81], the proton: sulfate symporter or putative sulfate: bicarbonate antiporter SulP [82, 83], and the high affinity sulfate transporter CysZ, essential for sulfate uptake at low concentrations $[84,85]$. No genes required for dissimilatory sulfate reduction were detected in the genome of strain OF001.

Rubrivivax sp. A210 harbours several genes required for assimilatory sulfate reduction, organised in three predicted operons (Additional file 1: Table S4). However, A210 lacks the adenylyl sulfate kinase cys $C$, responsible of the transformation of adenosine $5^{\prime}$-phosphosulfate

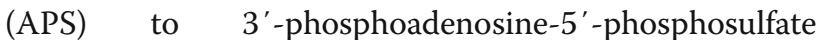
(PAPS), which is an essential step in the assimilatory sulfate reduction [86]. Nevertheless, other organisms like $P$. aeruginosa, Sinorhizobium meliloti, and Burkholderia cenocepacia lacking cys $C$, reduce APS via the phosphoadenosine phosphosulfate reductase $c y s H$ to sulphite [8789]. Strain A210 also possesses different sulfate transporters like ABC type UWA [81]. Similar to strain OF001 and other Rubrivivax species, not all genes involved in dissimilatory sulfate reduction were identified in strain A210.

\section{Iron metabolism}

Pseudomonas sp. OF001 possess genes predicted to participate in the transport and storage of iron, including ferrous and ferric iron transporters and bacterioferritin [90] (Additional file 1: Table S4). Strain OF001 also possesses different genes related to heme uptake, such as heme-binding protein and periplasmic heme chaperone [91]. AntiSmash analysis could not detect gene clusters related to siderophores synthesis in strain OF001 genome. Nonetheless, the search with blastp revealed the presence of thirty-one genes related to the synthesis and transport of siderophores. Twenty-one out of the thirtyone genes detected in the genome of strain OF001, correspond to siderophores transport (Additional file 1: Table S4).

Similar to strain OF001, the genome of Rubrivivax sp. A210 encodes genes predicted to participate in the transport and storage of iron, such as ferric iron transporters and bacterioferritin [90] (Additional file 1: Table S4). Strain A210 also possesses different genes related to heme uptake, such as heme-binding protein and periplasmic heme chaperone [91]. AntiSmash could not detect gene clusters related to siderophores synthesis in strain A210 genome. However, the search with blastp revealed the presence of thirty-six genes related to the synthesis and transport of siderophores. Twenty-two out of the thirty-six genes detected in A210 genome, correspond to siderophores transport (Additional file 1: Table S4).

\section{Cell motility and biofilm formation}

Proteins for motility, including genes related to chemotaxis, and flagellar proteins were present in the genome of Pseudomonas sp. OF001 (Additional file 1: Table S6). Genes encoding flagellar proteins in strain OF001 belong to the $f l g$, and fli family, which are part of the core set of flagellar genes [92]. Among the genes related to the central signal transduction pathway for chemotaxis, we found cheAWYBR genes, and the transmembrane chemoreceptors, methyl-accepting chemotaxis proteins (MCPs) in the genome of strain OF001. This is in agreement with the description of the closest relatives of strain OF001, P. oryzae, P. sagittaria, P. guangdongensis, and $P$. linyingensis, as motile bacteria $[68,69,93,94]$. Sixty-four genes associated with biofilm formation were found in the genome of Pseudomonas sp. OF001, including siaD, bifA, and fleQ (Additional file 1: Table S6).

In the genome of Rubrivivax sp. A210 genes required for motility were present, including genes related to chemotaxis, and genes encoding flagellar proteins (Additional file 1: Table S6). Similar as in strain OF001, in strain A210 found genes encoding flagellar proteins belong to the $f l g$, and fli family. Strain A210 possesses cheA WYBR genes, and the transmembrane chemoreceptors MCPs, which are related to the central signal transduction pathway for chemotaxis. The taxonomically closest bacteria to strain A210, R. gelatinosus, and $R$. benzoatilyticus, are also motile bacteria [41, 43]. However, despite the presence of motility-related genes in $R$. albus, the absence of motility was experimentally evidenced [42]. Therefore, further experiments are required to verify motility of strain A210. One hundred twenty one genes associated with biofilm formation were found in the genome of Rubrivivax sp. A210, including sadC, pilI, and pslH. (Additional file 1: Table S6).

As discussed above, both strains contain genes that encode proteins involve in biofilm formation, which is in agreement with the isolation of both MOB from biofilms. Moreover, both strains form biofilm in pure culture.

\section{Organic compound degradation}

Genes for the aerobic degradation of aromatic compounds via the catechol meta-cleavage pathway, and for the specific degradation of benzoate, phenol, and benzene, including phenol/toluene 2-monooxygenases (NADH), benzoate/toluate 1,2-dioxygenases, and catechol 2,3-dioxygenases, were detected in Pseudomonas sp. OF001 (Additional file 1: Table S7). In addition, 
strain OF001 may have the potential to transform other compounds like 2-, 3- and 4-fluorobenzoate, toluene, steroids, citalopram, trinitrotoluene, p-methylbenzoate, trans-cinnamate, phenylpropanoate, and 4hydroxyphenylacetate. This is in accordance with the ability of several Pseudomonas spp. to transform diverse organic pollutants such as benzoate, toluene, phenol, and poly- chlorobiphenyls (PCBs) [95].

Because strain OF001 is able to degrade the cyanotoxin CYN we were also interested in the potential of the strains to degrade other cyanobacterial toxins. However, specific enzymes for the degradation of cyanotoxins are described only for microcystin, the most studied cyanotoxin $[7,8]$. No genes involved in microcystin degradation were found in the genome of OF001. Although biodegradation of CYN is considered one of the main natural attenuation processes [96], no specific genes involved in their transformation are known yet [3].

Rubrivivax sp. A210 harbors genes involved in the aerobic degradation of aromatic compounds via the catechol ortho-cleavage pathway, and for the specific degradation of benzoate, and 3- and 4-fluorobenzoate, including benzoate/toluate 1,2-dioxygenases, muconate cycloisomerase, and catechol 1,2-dioxygenase (Additional file 1: Table S7). Similarly, the closely-related strain $R$. bezoatilyticus JA2 catabolizes different aromatic compounds including benzoate [41]. Strain A210 also has the potential to transform other compounds such as 4-methylcatechol, acrylonitrile, 2-fluorobenzoate, and trinitrotoluene.

Because strain A210 is able to degrade CYN similarly as strain OF001, we searched the genome for genes related to cyanotoxin transformation. We could not find genes associated with the transformation of microcystin.

\section{Elements potentially acquired by horizontal gene transfer Genomic islands}

Genomic islands are genomic regions potentially obtained by horizontal gene transfer that can drive strain differentiation and support adaptation. Analysis of Pseudomonas sp. OF001 genome with IslandViewer 4 led to the identification of at least 12 genomic islands with size ranges from 4.2 to $70.5 \mathrm{~Kb}$ (Additional file 1: Table S8 and Fig. S6a). Genomic islands in strain OF001 include genes associated with transposases, phage proteins, CRISPR systems, 147 proteins of unknown function, toxin-antitoxin systems, metal-related proteins, and mercury resistance. Metal resistance genes are related with environmental pollution, and specifically, mercury resistance genes are the genes most frequently associated with genomic islands [97].

Analysis of Rubrivivax sp. A210 genome with IslandViewer 4 led to the identification of at least 8 genomic islands with size ranges from 3.8 to $99.5 \mathrm{~Kb}$ (Additional file 1: Table S8 and Fig. S6b). Genomic islands in strain A210 included genes associated with transposases, phage proteins, 136 proteins of unknown function, toxinantitoxin systems, transporters, and nitrate reduction. Genes related to nitrogen metabolism associated to genomic island have been previously reported $[98,99]$.

\section{Prophages}

Using PHASTER (PHAge Search Tool Enhanced Release), we detected four incomplete and three intact prophage regions (Score $\geq 100$ ) in Pseudomonas sp. OF001 genome (Additional file 1: Table S9 and Fig. S7a). The three intact prophages were named OF001 region 2, OF001 region 5, and OF001 region 7 based on the genome location retrieved by PHASTER. A summary of the distribution and genetic features of these prophages is shown in Additional file 1: Fig. S7b. All prophages in OF001 exhibited structural proteins, including major capsid, fiber, and tail proteins.

Based on the proteomic tree generated with the VIPTree server, all complete prophages in OF001 belong to the order Caudovirales (Additional file 1: Fig. S8). OF001 region 2 and OF001 region 5 were classified in the family Siphoviridae, while OF001 region 7 was classified in the family Myoviridae. Interestingly, OF001 region 2 and OF001 region 7 display putative site-specific integrases and excisionases, indicating site-specific recombination [100]. Multiple prophages have already been observed in other members of the genus Pseudomonas [101-104].

Within A210 genome, two incomplete prophages of 28.8 and $9.9 \mathrm{~kb}$ were detected (Additional file 1: Table S9 and Fig. S7c). No complete prophage was identified.

\section{CRISPR-Cas systems}

Using the CRISPRCas finder tool, we identified one complete class 1 CRISPR-Cas system, with a level of confidence of 4 (levels from 1 to 4 , representing level 4 the most confident identification [105]) in the genome of OF001 (Additional file 1: Table S10 and S11). The seven cas genes are downstream of the repeat/spacer region. The repeats and spacers were compared with the CRISPRCas database [106] and were highly similar to sequences found in other bacteria including some Pseudomonads like $P$. stutzeri, $P$. aeruginosa, and Pseudomonas sp. phDV1 (Additional file 1: Table S12 and S13). From the taxonomically closest organisms to strain OF001, only P. guandongensis has one confirmed class 1 CRIS $\mathrm{PR} /$ Cas system.

In the genome of A210, one complete class 1 CRISPRCas system, with a level of confidence of 4 , and one CRISPR region without cas genes associated, with a level of confidence of 2 were identified (Additional file 1: Table S10 and S11). The three cas genes associated to 
the complete CRISPR-Cas loci are downstream of the repeat/spacer region. The repeats and spacers of the CRIS PR region with a level of confidence 4 were compared with the CRISPRCas database [106] and, for the majority of them, no matching were found (Additional file 1: Table S14 and S15). For the three spacers and two repeats, only results with a similarity around $50 \%$ were found. The organisms were these repeats and spacers were found are Verrucomicrobium spinosum, Raphidiopsis curvata, Pectobacterium carotovorum and Opitutaceae bacterium. The taxonomically closest organisms to strain A210, R. gelatinosus and $R$. benzoatilyticus, have two CRISPRs without associated cas genes, and 4 incomplete and 2 complete CRISPR-Cas systems, respectively.

Class 1 CRISPR-Cas systems, as the one found in both $\mathrm{MOB}$, are the most abundant class in Beta and Gammaproteobacteria, and in general in archaea and bacteria [107].

The presence of CRISPR-Cas systems in strain OF001 and A210 might represent protection from phage infections, but could represent a disadvantage if useful genes for competitive adaptation cannot be acquired via external DNA [108].

Together the presence of genomic islands, including phage material and CRISPR-Cas systems in Pseudomonas sp. OF001 and Rubrivivax sp. A210 suggest that both MOB have undergone diverse genetic changes related to different horizontal gene transfer mechanisms which likely contribute to their genome plasticity.

\section{Implications of the metabolic potential of strains OF001 and $\mathrm{A} 210$}

In this study, we aimed at a better understanding of the metabolic capacities of the two CYN removing $\mathrm{MOB}$ which could potentially contribute to the biotechnological use of MOB for the removal of pollutants from water. In agreement with the genomes of other MOB with so far uncharacterized degradation ability [35, 36], the content of the genomes of strain OF001 and strain A210 suggests a potential metabolic versatility and thus, a broader application potential.

The genomic potential of MOB strains OF001 and A210 for the degradation of different organic compounds via specific enzymatic pathways might complement the unspecific transformation pathways of substances like diclofenac [109] and CYN [2, 3], via manganese oxidation. Our results suggest that strain OF001 and A210 might be able to remove different organic pollutants by a coupled mechanism involving specific enzymatic activity and unspecific oxidation by the reactive manganese species, as has been observed for the removal of phenolic compounds, which are common wastewater pollutants [110]. Moreover, it seems likely that the MOB described in this study transform other organic compounds like carbofuran, ciprofloxacin, and $17 \alpha$-ethinylestradiol, similar to other MOB $[30,111$, $112]$.

Both analyzed MOB, strain OF001 and A210, transform $\mathrm{CYN}$ indirectly through the oxidation of $\mathrm{Mn}^{2+}[3]$, and according to the results of this study most likely mediated by the activity of multicopper oxidases and haem peroxidases. The unspecific transformation of CYN by MOB does not require an adaptation phase or a preconditioned towards the toxin as it is known for many enzymatically catalyzed processes. Therefore, the use of MOB to remove the only periodically occurring CYN molecule, might represent an advantage in comparison to other biological removal processes that require a preconditioning with the toxin to remove it. Moreover, the unspecific oxidation of organic pollutants via reactive manganese species might allow for the removal of other cyanotoxins, however further studies are required.

The different metabolic pathways encoded in the genome of strain OF001 and strain A210 also suggest different fields of application aiming at the removal of pollutants. For instance, the ability of strain A210 to thrive and degrade CYN in the absence of an organic carbon source suggests that it is more suitable for an application in settings, in which readily degradable organic carbon sources are depleted, such as reactors for the removal of pollutants from secondary wastewater. Also, due to the metabolic potential of strain A210, it may adapt within the reactor or the biofilm to varying oxygen concentrations or even the depletion of oxygen by a shift to nitrate respiration [113]. Moreover, both strains are able to form biofilms which may allow them to establish and be retained on fixed bed reactors.

Pseudomonas sp. OF001 showed the highest CYN removal efficiency and the fastest growth from all tested MOB [2]. Furthermore, it was isolated from a fixed-bed reactor system, however, the genome of strain OF001 encodes less diverse metabolic pathways to adapt to changing environments. Together, this data suggests that studies investigating degradation potential of $\mathrm{MOB}$ should consider the phylogenetic and metabolic diversity of MOB to identify the most suitable organisms that fulfil the requirements of the removal system.

The metabolic diversity of strains OF001 and A210 also suggests an important role of MOB in the removal of CYN in different habitats. For instance, strain A210 was isolated from a freshwater lake in the National Park Lower Oder Valley in Germany. This strain has the metabolic potential to dissimilatory reduced nitrate, which is an important mechanism to control nitrogen loading in aquatic environments [114-116]. Dissimilatory nitrate reduction to ammonium has been related to the promotion of eutrophic conditions in water systems, due to the release of ammonium that could be used 
preferentially by cyanobacteria, and therefore favouring cyanobacterial blooms [116]. MOB strains with the ability to denitrify and degrade CYN may be therefore tightly interconnected with the production and removal of the cyanotoxin. Furthermore, the metabolic versatility of MOB may allow them to inhabit sediments and water columns. Therefore, MOB might contribute to the removal of CYN produced by benthic organisms in sediments, but also might transform CYN produced by planktonic cyanobacteria in the water column. However, further studies on the occurrence and distribution of $\mathrm{MOB}$ in $\mathrm{CYN}$ contaminated environments are required.

\section{Conclusions}

In summary, this study provides an insight into the molecular basis of $\mathrm{Mn}^{2+}$ oxidation, and into the metabolic potential of two CYN-transforming MOB strains. We identified sequences in Pseudomonas sp. OF001 and Rubrivivax sp. A210 that show high similarity to already described MCOs which may catalyze manganese oxidation required for CYN transformation. Furthermore, considering the mechanism proposed for the removal of other pollutants by MOB the multicopper oxidases found in both strains and the haem peroxidase identified in strain OF001 might covey the ability to both strains to transform also other pollutants susceptible to reactive $\mathrm{Mn}$ species. Both MOB share the potential to grow over a wide range of $\mathrm{O}_{2}$ concentrations, to fix nitrogen, and reduce nitrate and sulfate via the assimilatory pathway. Both strains encode pathways that might enable them to remove different aromatic compounds such as benzoate, benzene, and phenol. However, while strain A210 harbors the genomic potential to fix $\mathrm{CO}_{2}$ and to reduce nitrate as final respiratory electron acceptor, strain OF001 requires additional organic carbon sources and lacks the ability for dissimilatory nitrate reduction. The analysis of the general metabolism of two MOB strains able to remove organic pollutants such as CYN and DCF might help to implement MOB in biotechnological applications and contributes to a better understanding of the natural niches of CYN-removing MOB in natural habitats.

\section{Methods}

Strains, culturing conditions and genomic DNA extraction Pseudomonas sp. OF001 and Rubrivivax sp. A210 were obtained from the culture collection of the Laboratory of Environmental Microbiology from the TU Berlin, Germany [2]. Bacteria were routinely cultivated in a medium that was originaly developed for Leptothrix strains [117], which was modified by our research group and is known as LSM2.

Cells from a pure, fresh $50 \mathrm{~mL}$ liquid culture from each strain were harvested by centrifugation at $15,000 \mathrm{x}$ $g$ for $3 \mathrm{~min}$ and washed three times with sterile Milli Q water under sterile conditions. Total genomic DNA was extracted using the GeneMATRIX Soil DNA Purification Kit $\left(E U R_{X}\right.$ Gdańsk, Poland) following the manufacturer's instructions. Quality and quantity of the extracted DNA was determined using QubitTM fluorometric quantitation and NanoDrop 2000 (both Thermo Fisher Scientific, Bremen, Germany).

\section{Genome sequencing, assembly and annotation}

The genome of both MOB strains was sequenced on an Illumina MiSeq platform with a read length of $301 \mathrm{bp}$ (paired end). The genome of each isolate was assembled using SPAdes 3.10.1 and draft genomes obtained using manual binning procedures based on coverage-GC plots performed in R 3.6.1 (Additional file 1: Fig. S9). Genome quality estimation based on completeness and contamination was determined with CheckM [118]. Genome annotation was performed with the interface Magnifying Genomes (MaGE) of the MicroScope web-based service from GenoScope [119]. Protein coding genes were classified based on the annotation into Cluster of Orthologous Groups (COG) functional categories [120] with the automatic classification COG tool at Microscope platform. Function and pathway analysis were performed using BlastKOALA web tool of KEGG (Kyoto Encyclopedia of Genes and Genomes) database according to the KEGG groups of orthologs [121], and using MicroCyc tool of the MicroScope web-based service from GenoScope [119] which is a collection of microbial Pathway/Genome databases (PGDBs). PGDBs within MicroScope are generated by comparing the genome annotations to the metabolic reference database MetaCyc [122]. In the present work, metabolic potential will refer to the possibility of the strains to follow a specific metabolic pathway based only on their genome information, without being so far experimentally corroborated.

The data for this study have been deposited in the European Nucleotide Archive (ENA) at EMBL-EBI under project number PRJEB40009 with accession numbers GCA_904426495 and GCA_904426505 for strain OF001 and A210, respectively (https://www.ebi.ac.uk/ ena/browser/view/PRJEB40009).

\section{Genomes comparison}

First classification of the genomes was determined according to the Genome Taxonomy Database (GTDB) using the GTDB-tool kit (GTDB-tk) v.1.1.0 integrated in the MicroScope web-based service [44, 123, 124]. GTDB-tk provides a taxonomic classification of bacterial and archaeal genomes based on the combination of the GTDB reference tree, the relative evolutionary divergence and the ANI value against reference genomes [123]. GTDB proposed a bacterial taxonomy based on the phylogeny inferred from the concatenation of 120 
ubiquitous single-copy proteins that normalizes taxonomic ranks by using the relative evolutionary divergence [124]. Therefore, it is considered that the analysis performed by GTDB-tk has an advantage over other phylogenies currently in use [124].

Genomes sequences were uploaded to the Type strain genome server (TYGS), a free bioinformatics platform (https://tygs.dsmz.de) for a whole genomebased taxonomic analysis [125]. TYGS platform runs automatically all the analysis. Briefly, TYGS performed first a determination of closely related type strain genomes, comparing the query genome against all available genomes in the TYGS database with the MASH algorithm [126] and selecting ten type strains. Then, additionally ten close related type strains were determined based on the 16S rRNA sequence extracted from the query genome using RNAmmer [127]. 16S rRNA sequences were compared with BLAST [128] against the TYGS database. The best 50 matching types were used to calculate precise distances using the Genome BLAST distance phylogeny approach (GBDP) [37]. The distances calculated by GBDP were then used to determine the ten closest type strain genomes for each query. Afterwards, GBDP conducted all pairwise comparisons among the set of genomes selected in the previous steps, and inferred accurate intergenomic distances under the algorithm "trimming" and distance formula $d_{5}$ [37]. One hundred distance replicates were calculated each. In silico DNA-DNA hybridization (DDH) analysis were calculated using the recommended settings of the Genome-to-genome distance calculator (GGDC) 2.1 [37]. The resulting intergenomic distances were used to infer a balanced minimum evolution tree with branch support via FASTME 2.1.4 including subtree pruning and regrafting (SPR) postprocessing [129]. Branch support was inferred from 100 pseudo-bootstrap replicates each.

JSpeciesWS [40] was used to calculate the average nucleotide identity (ANI) values [40] based on BLAST (ANIb) [38, 128] and MUMmer (ANIm) [130], and to calculate the correlation indexes of the tetra-nucleotide frequencies (TETRA) [131].

For the ANI and TETRA analysis, the genome of strain OF001 was compared to the Pseudomonads belonging to the Pseudomonas_K group: P. oryzae (GCA 900104805.1), $\quad$ P. sagittaria (GCA_900109175.1), $\quad$ P. guangdongensis (GCA_900105885.1), and P. liyingensis (GCA_900115715.1).

For the ANI and TETRA analysis, the genome of strain A210 was compared to the genomes of the three species of the genus Rubrivivax: $R$. benzoatilyticus JA2 (GCA_000420125.1), $R$. gelatinosus IL144 (GCA 000284255.1), $R$. gelatinosus DSM 1709 (GCA 00430905.1), and $R$. albus ICH-03 (GCA_004016515.1).

\section{Core- and pan-genome}

Determination of the core- and pan-genome analysis was performed with the Pan/Core-genome tool from the MicroScope web-based service [119]. The analysis is based on the computation of Microscope gene families (MICFAM) using a single linkage clustering algorithm of homologous genes sharing an amino-acid alignment coverage and identity above the defined threshold [45]. This analysis considered i) any MICFAM associated with at least one gene from every genome used for the comparison as a part of the core-genome, ii) any MICFAM associated with at least 2 compared genomes as a part of the variable- genome, and iii) the sum of the coregenome and variable-genome as the pan-genome [44]. Parameter of 50/80 was selected (50\% amino-acid identity, $80 \%$ amino-acid alignment coverage). All bacterial genomes used for the comparison with the genomes of strain OF001 or strain A210 that were not available in the MicroScope database were also annotated with MaGe from GenoScope [119].

For the pan- and core-genome analysis, the same strains as for the ANI and TETRA analysis, were used.

\section{Manganese-oxidation genes}

We used the blastp function on the Microscope web server $[128,132]$ to identify potential $\mathrm{Mn}^{2+}$ oxidases in Pseudomonas sp. OF001 and Rubrivivax sp. A210, using experimentally verified $\mathrm{Mn}^{2+}$ oxidases of other manganese-oxidizing bacteria. Nine sequences of multicopper oxidases and three sequences of haem peroxidases related with the oxidation of $\mathrm{Mn}^{2+}$ in other $\mathrm{MOB}$ were used for the search (Table S1). Multicopper oxidases and haem peroxidases with $\mathrm{Mn}^{2+}$ oxidation activity will be referred as MO-mco and MO-hpox, respectively. We considered as homologue any protein with an E-value lower than $10^{-10}$.

$\mathrm{Mn}^{2+}$ oxidases and putative homologues found in OF001 and A210 were functionally analyzed with the InterPro web server [133]. InterPro web server classifies proteins into families, and predicts functional domains and important sites of the proteins, integrating protein signatures from 13 different databases. We predicted the sub-cellular localization with LocTree3 [52] of those putative homologues without a predicted cytoplasmic or non-cytoplasmic domain according to the InterPro analysis.

To determine a possible phylogenetic relationship between manganese-oxidizing multicopper oxidases (MOmco) and non-manganese oxidizing multicopper oxidases (non-MO-mco), we created a dataset sequences of multicopper oxidases with experimental evidence of $\mathrm{Mn}^{2+}$ oxidation $[47-49,53,134,135]$ and multicopper oxidases with experimental evidence of non- $\mathrm{Mn}^{2+}$ oxidation activity $[47,54]$ and included our sequences. They 
were aligned using MUSCLE [136] in MEGA v7.0.25. A phylogenetic tree was constructed with Maximum Likelihood method in MEGA v7.025. A bootstrap analysis was performed with 1000 replicates for the Maximum Likelihood tree.

\section{Operon prediction}

Operon prediction was done using the FGENESB program [137]. FGENESB gene prediction algorithm is based on Markov chain models of coding regions, start of translation, and termination sites. Predicted genes are then used for the operon models using distances between ORFs frequencies of neighboring genes in known bacterial genomes, and positions of predicted promoters and terminators [137].

\section{Siderophores}

Identification of siderophore biosynthesis gene clusters was performed with AntiSMASH tool [138] from the MicroScope web-based service. In addition, we used the blastp function on the Microscope web server $[128,132]$ to search for genes previously reported for the biosynthesis of siderophores pyoverdine, enterobactin, yersiniabactin, ornibactin and pyochelin [139-142].

\section{Elements potentially acquired by horizontal gene transfer Genomic islands}

Genomic islands were predicted with the IslandPathDIMOB [143] and SIGI-HMM [144] method included in the IslandViewer 4 tool using the default settings [145]. Among the prediction methods included in IslandViewer 4 tool, SIGI-HMM has the highest precision and overall accuracy [146].

\section{Prophages}

Putative phages from Pseudomonas sp. OF001 and Rubrivivax sp. A210 were predicted with PHASTER (PHAge Search Tool Enhanced Release) web server [147]. PHASTER classifies genome regions with a score below 70 as incomplete, between 70 to 90 as questionable, and greater than 90 as complete prophages [147].

The resulting complete prophage genomes were annotated with multiPhATE v.1.0 (multiple-genome Phage Annotation Toolkit and Evaluator) [148] using Phanotate to predict ORFs [149]. PhAnToMe (Phage Annotation Tools and Methods), pVOGs [150], and SwissProt [151] databases were used for the identification of the homologs of the input genomes and its predicted gene and peptide sequences. Additionally, highly divergent structural proteins were detected with iVireons [152] and confirmed with VIRALPro [153].

To classify the complete prophages, a whole proteomic tree based on genome-wide similarities was computed by tBLASTx, using the VIPTree web server v.1.9 [154].

\section{CRISPR-Cas systems}

The presence of Clustered Regularly Interspaced Short Palindromic Repeats (CRISPR) and their associated genes (cas) was evaluated with CRISPRCasFinder [105]. CRISPRCasFinder include a rating system which classifies the detected CRISPRs to differentiate between CRIS PR-like elements and true CRISPRs. Evidence levels from 1 to 4 are assigned, with 1 representing the lowest evidence classification and 4 the most confident identification [105].

Spacers and repeat regions detected in both genomes were searched with BLAST (blastn) against the CRIS PRCasdb to identify their presence in other organisms. CRISPRCasdb contains CRISPR arrays and cas genes from complete genome sequences [106].

\section{Data graphics}

Figures were made with the $\mathrm{R}$ packages ggplot2 (Wickham, 2016), gridExtra (Auguie, 2017), pheatmap [155], VennDiagram [156], and gggenes [157], using Viridis [158] and RcolorBrewer [159] packages for colouring in RStudio version 1.0.153 [160, 161]. Genomic maps of prophages were generated using the Snapgene ${ }^{\oplus}$ software (GSL Biotech). Trees generated with the TYGS tool and the multicopper oxidase tree were visualized and annotated with the online server iTOL [162].

\section{Supplementary Information}

The online version contains supplementary material available at https://doi. org/10.1186/s12864-021-07766-0.

\footnotetext{
Additional file 1: Fig. S1. Phylogenetic tree based on 16S rDNA sequences and whole genome sequences including strain OF001 sequence. Tree inferred with FastME 2.1.6.1 [129] from GBDP distances calculated from a) 165 rDNA gene sequences and b) genome sequences. The branch lengths are scaled in terms of GBDP distance formula $d_{5}$. The numbers above branches are GBDP pseudo-bootstrap support values > $60 \%$ from 100 replications, with an average branch support of a) $68.8 \%$ and b) $92.5 \%$. Tree was rooted at the midpoint [163]. Bold text represent the sequences generated in the present work. Scale bar represent sequence divergence. Fig. S2. Phylogenetic tree based on 165 rDNA sequences and whole genome sequences including strain A210 sequence. Tree inferred with FastME 2.1.6.1 [129] from GBDP distances calculated from a) $16 \mathrm{~S}$ rDNA gene sequences and b) genome sequences. The branch lengths are scaled in terms of GBDP distance formula $d_{5}$. The numbers above branches are GBDP pseudo-bootstrap support values > $60 \%$ from 100 replications, with an average branch support of a) $76.8 \%$ and b) $83.4 \%$. Tree was rooted at the midpoint [163]. Bold text represent the sequences generated in the present work. Scale bar represent sequence divergence. Fig. S3. Pan- and core genome overview. Venn diagram shows the number of shared and specific Microscope gene families (MICFAM) a) among Pseudomonas sp. OF001 and the members of the Pseudomonas_K group, and b) among Rubrivivax sp. A210 and the members of the Rubrivivax genus. MICFAM grouping was based on 50\% amino acid identity cut-off and at least $80 \%$ amino-acid alignment coverage. Fig. S4. Pan- and core- genome sizes estimated evolution. a, c) Number of MICFAM families in the pan-genome size by the number of genomes, and $b, d$ ) number of MICFAM families in the core-genome by the number of genomes. a, b) Including Pseudomonas sp. OF001, and c, d) including Rubrivivax sp. A210. Fig. S5. Maximum Likelihood phylogenetic tree based on multicopper oxidases sequences with and without reported
} 
$\mathrm{Mn}^{2+}$ oxidation activity. Sequences of the studied strains in the present study are not included. Numbers in the branches represent bootstrap value. Scale bar represent sequence divergence. Fig. S6. Putative genomic islands harbored by the studied MOB. a) Pseudomonas sp. OF001, and b) Rubrivivax sp. A210. Outer circle represents the genome size in Mbps. Genomic islands obtained by different prediction methods are highlighted in color. Integrated represent those islands detected by at least one method. Fig. S7. Distribution and genetic features of prophages detected in Pseudomonas sp. OF001 and Rubrivivax sp. A210. a) Circular genome map of strain OF001, b) genetic features of the complete prophages in strain OF001, and b) circular genome map of strain A210. In the genome maps location of prophages are highlighted in colors depending on the completeness of the prophages (Table S9). Number assigned to each prophage region is based on the genome location retrieved by PHASTER [147]. Fig. S8. Whole proteomic tree of Pseudomonas sp. OF001 prophages based on genome-wide similarities computed by tBLASTX. The tree was constructed using the VIPTree web server v.1.9 [154]. Numbers in brackets in the figure legend represent the number of virus genomes. Red stars represent the three complete prophages of strain OF001. Scale bar represent sequence divergence. Fig. S9. Coverage-GC plots of contig properties for strain OF001 and A210. a, c) Coverage vs GC content, and b, d) coverage vs length. Both samples has a primary, high abundance cluster of contigs, with GC centered around 0.6 with arise form the primary culture populations. For strain OF001 a second contig cluster with GC centered around 0.35 at a much lower abundance was detected, which might represent a slight DNA contamination. Table S1. List of genes in strains OF001 and A210 with homology to putative $\mathrm{Mn}^{2+}$ oxidases from other MOB. Table S2. Functional domains and ontology classification of MO-mco and MO-hpox from

MOB. Table S3. List of sequences of MO-mco and non- $\mathrm{Mn}^{2+}$ oxidases.

Table S4. List of genes related to the metabolic potential of Pseudomonas sp. OF001 and Rubrivivax sp. A210. Table S5. List of cytochrome genes within Pseudomonas sp. OF001 and Rubrivivax sp. A210. Table S6. List of genes related to cell motility and biofilm formation within Pseudomonas sp. OF001 and Rubrivivax sp. A210. Table S7. List of genes related to degradation of organic compounds in Pseudomonas sp. OF001 and Rubrivivax sp. A210. Table S8. Genomic islands identified within Pseudomonas sp. OF001 and Rubrivivax sp. A210 genome sequences. Table S9. Characteristics of prophage regions identified in Pseudomonas sp. OF001 and Rubrivivax sp. A210 genome. Table S10. CRISPR-Cas systems detected within Pseudomonas sp. OF001 and Rubrivivax sp. A210 genome. Table S11. Characteristics of the cas genes detected within Pseudomonas sp. OF001 and Rubrivivax sp. A210 genome. Table S12. Comparison of repeats in the CRISPR of confidence level 4 found in strain OF001 to CRISPRCasdb. Table S13. Comparison of spacers in the CRISPR of confidence level 4 found in strain OF001 to CRISPRCasdb. Table S14. Comparison of repeats in the CRISPR of confidence level 4 found in strain A210 to CRISPRCasdb. Table S15. Comparison of spacers in the CRISPR of confidence level 4 found in strain A210 to CRISPRCasdb.

\section{Acknowledgments}

The LABGeM (CEA/Genoscope \& CNRS UMR8030), the France Génomique and French Bioinformatics Institute national infrastructures (funded as part of Investissement d'Avenir program managed by Agence Nationale pour la Recherche, contracts ANR-10-INBS-09 and ANR-11-INBS-0013) are acknowledged for support within the MicroScope annotation platform.

\section{Authors' contributions}

EBMR discussed the conceptualization and methodology of the project, extracted the DNA and performed all the bioinformatic analysis except those related with the phages and the assembly of the genomes, and wrote the original draft including all tables and figures. MC supervised and discussed the conceptualization and methodology of the project, and participated in the revision and edition of the manuscript. JBC performed the analysis related with the phages, and participated in the revision of the manuscript. $\mathrm{IB}$ coordinated the sequencing submission, and participated in the revision of the manuscript. MASH performed the assembly of the genomes, and participated in the revision of the manuscript. RW provided resources for the research, and participated in the revision of the manuscript. US supervised, provided resources for the research, and participated in the revision and edition of the manuscript. The author(s) read and approved the final manuscript.

\section{Funding}

Erika B. Martinez-Ruiz was supported by a research scholarship from the DAAD (Deutscher Akademischer Austauschdienst). Contributions of Mindia A. S. Haryono, Irina Bessarab, and Rohan B. H. Williams are funded by the Singapore National Research Foundation and Ministry of Education under the Research Centre of Excellence Programme. We acknowledge support by the German Research Foundation and the Open Access Publication Fund of TU Berlin. Open Access funding enabled and organized by Projekt DEAL.

\section{Availability of data and materials}

The data for this study have been deposited in the European Nucleotide Archive (ENA) at EMBL-EBI under project number PRJEB40009 with accession numbers GCA_904426495 and GCA_904426505 for strain OF001 and A210, respectively.

\section{Declarations}

Ethics approval and consent to participate

Not applicable.

\section{Consent for publication}

Not applicable.

\section{Competing interests}

The authors declare that they have no competing interests.

\section{Author details}

${ }^{1}$ Chair of Environmental Microbiology, Technische Universität Berlin, Institute of Environmental Technology, Straße des 17. Juni 135, 10623 Berlin, Germany. ${ }^{2}$ Singapore Centre for Environmental Life Sciences Engineering, National University of Singapore, Singapore 119077, Singapore.

Received: 9 October 2020 Accepted: 3 June 2021

Published online: 22 June 2021

\section{References}

1. Poniedziałek B, Rzymski P, Kokociński M. Cylindrospermopsin: water-linked potential threat to human health in Europe. Environ Toxicol Pharmacol. 2012;34(3):651-60. https://doi.org/10.1016/j.etap.2012.08.005.

2. Martínez-Ruiz EB, Cooper M, Fastner J, Szewzyk U. Manganese-oxidizing bacteria isolated from natural and technical systems remove cylindrospermopsin. Chemosphere. 2020;238:124625. https://doi.org/10.101 6/j.chemosphere.2019.124625.

3. Martínez-Ruiz EB, Cooper M, Al-Zeer MA, Kurreck J, Adrian L, Szewzyk U. Manganese-oxidizing bacteria form multiple cylindrospermopsin transformation products with reduced human liver cell toxicity. Sci Total Environ. 2020;729:138924. https://doi.org/10.1016/j.scitotenv.2020.138924.

4. Mohamed ZA, Alamri SA. Biodegradation of cylindrospermopsin toxin by microcystin-degrading bacteria isolated from cyanobacterial blooms. Toxicon. 2012;60(8):1390-5. https://doi.org/10.1016/j.toxicon.2012.10.004.

5. Dziga D, Kokocinski M, Maksylewicz A, Czaja-Prokop U, Barylski J. Cylindrospermopsin biodegradation abilities of Aeromonas sp. isolated from Rusałka Lake. Toxins (Basel). 2016:8:55.

6. Nybom SMK, Salminen SJ, Meriluoto JAO. Specific strains of probiotic bacteria are efficient in removal of several different cyanobacterial toxins from solution. Toxicon. 2008;52:214-20.

7. Kumar P, Hegde K, Brar SK, Cledon M, Kermanshahi-pour A. Potential of biological approaches for cyanotoxin removal from drinking water: a review. Ecotoxicol Environ Saf. 2019;172:488-503. https://doi.org/10.1016/j.ecoenv.2 019.01.066.

8. Kormas KA, Lymperopoulou DS. Cyanobacterial toxin degrading bacteria: who are they? Biomed Res Int. 2013;2013:463894.

9. Yang W, Zhang Z, Zhang Z, Chen H, Liu J, Ali M, et al. Population structure of manganese-oxidizing bacteria in stratified soils and properties of manganese oxide aggregates under manganese-complex medium enrichment. PLoS One. 2013:8(9):e73778. https://doi.org/10.1371/journal. pone.0073778. 
10. Tebo BM, Johnson HA, McCarthy JK, Templeton AS. Geomicrobiology of manganese(II) oxidation. Trends Microbiol. 2005;13:421-8.

11. Hansel CM, Learman DR. Geomicrobiology of manganese. In: Ehrlich $H$, Newman D, Kappler A, editors. Ehrlich's Geomicrobiology. 6th ed. Boca Raton: CRC Press; 2015. p. 403-33.

12. Schmidt B, Sánchez LA, Fretschner T, Kreps G, Ferrero MA, Siñeriz F, et al. Isolation of Sphaerotilus-Leptothrix strains from iron bacteria communities in Tierra del Fuego wetlands. FEMS Microbiol Ecol. 2014;90:454-66.

13. Szewzyk U, Szewzyk R, Schmidt B, Braun B. Neutrophilic iron-depositing microorganisms. In: Flemming H-C, Wingender J, Szewzyk U, editors. Biofilm highlights. Springer: Berlin Heidelberg; 2011. p. 63-79. https://doi.org/10.1 007/978-3-642-19940-0.

14. Cerrato JM, Falkinham JO, Dietrich AM, Knocke WR, McKinney CW, Pruden A. Manganese-oxidizing and -reducing microorganisms isolated from biofilms in chlorinated drinking water systems. Water Res. 2010;44: 3935-45.

15. Tobiason JE, Bazilio A, Goodwill J, Mai X, Nguyen C. Manganese removal from drinking water sources. Curr Pollut Reports. 2016;2(3):168-77. https:// doi.org/10.1007/s40726-016-0036-2.

16. Zhang Y, Zhu H, Szewzyk U, Geissen SU. Removal of pharmaceuticals in aerated biofilters with manganese feeding. Water Res. 2015;72:218-26. https://doi.org/10.1016/j.watres.2015.01.009.

17. Tebo BM, Bargar JR, Clement BG, Dick GJ, Murray KJ, Parker D, et al. Biogenic manganese oxides: properties and mechanisms of formation. Annu Rev Earth Planet Sci. 2004;32(1):287-328. https://doi.org/10.1146/annurev.ea rth.32.101802.120213.

18. Zhou H, Fu C. Manganese-oxidizing microbes and biogenic manganese oxides: characterization, $\mathrm{Mn}(\mathrm{II})$ oxidation mechanism and environmental relevance. Rev Environ Sci Bio/Technol. 2020;1(3):489-507. https://doi.org/1 0.1007/s11157-020-09541-1.

19. Hennebel T, De Gusseme B, Boon N, Verstraete W. Biogenic metals in advanced water treatment. Trends Biotechnol. 2009;27:90-8.

20. Lee $S, X u H . X R D$ and TEM studies on nanophase manganese oxides in freshwater ferromanganese nodules from Green Bay, Lake Michigan. Clays Clay Miner. 2016;64:523-36

21. Stein LY, La Duc MT, Grund TJ, Nealson KH. Bacterial and archaeal populations associated with freshwater ferromanganous micronodules and sediments. Environ Microbiol. 2001;3:10-8.

22. Kepkay PE, Nealson KH. Growth of a manganese oxidizing Pseudomonas sp. in continuous culture. Arch Microbiol. 1987;148:63-7.

23. Banh A, Chavez V, Doi J, Nguyen A, Hernandez S, Ha V, et al. Manganese $(\mathrm{Mn})$ oxidation increases intracellular $\mathrm{Mn}$ in Pseudomonas putida GB-1. PLoS One. 2013:8:e77835.

24. Zerfaß C, Christie-Oleza JA, Soyer OS. Manganese oxide biomineralization provides protection against nitrite toxicity in a cell-density-dependent manner. Appl Environ Microbiol. 2019;85:5-8

25. Jones ME, Nico PS, Ying S, Regier T, Thieme J, Keiluweit M. Manganesedriven carbon oxidation at oxic-anoxic interfaces. Environ Sci Technol. 2018; 52:12349-57.

26. Sunda WG, Kieber DJ. Oxidation of humic substances by manganese oxides yields low-molecular-weight organic substrates. Nature. 1994;367:62-4.

27. Estes ER, Andeer PF, Nordlund D, Wankel SD, Hansel CM. Biogenic manganese oxides as reservoirs of organic carbon and proteins in terrestrial and marine environments. Geobiology. 2017;15:158-72.

28. Geszvain K, Butterfield C, Davis RE, Madison AS, Lee S-W, Parker DL, et al. The molecular biogeochemistry of manganese(II) oxidation. Biochem Soc Trans. 2012:40(6):1244-8. https://doi.org/10.1042/BST20120229.

29. Meerburg F, Hennebel T, Vanhaecke L, Verstraete W, Boon N. Diclofenac and 2-anilinophenylacetate degradation by combined activity of biogenic manganese oxides and silver. Microb Biotechnol. 2012;5(3):388-95. https:// doi.org/10.1111/j.1751-7915.2011.00323.x.

30. Tran TN, Kim DG, Ko SO. Synergistic effects of biogenic manganese oxide and $\mathrm{Mn}(\mathrm{II})$-oxidizing bacterium Pseudomonas putida strain MnB1 on the degradation of 17 a-ethinylestradiol. J Hazard Mater. 2018;344:350-9. https://doi.org/10.1016/j.jhazmat.2017.10.045.

31. Watanabe J, Tani Y, Chang J, Miyata N, Naitou H, Seyama H. As(III) oxidation kinetics of biogenic manganese oxides formed by Acremonium strictum strain KR21-2. Chem Geol. 2013;347:227-32. https://doi.org/10.1016/j. chemgeo.2013.03.012.

32. Wang $H$, Lv Z, Song $Y$, Wang $Y N$, Zhang $D$, Sun $Y$, et al. Adsorptive removal of $\mathrm{Sb}$ (III) from wastewater by environmentally-friendly biogenic manganese oxide (BMO) materials: efficiency and mechanisms. Process Saf Environ Prot. 2019;124:223-30. https://doi.org/10.1016/j.psep.2019.02.022.

33. Wang R, Wang S, Tai Y, Tao R, Dai Y, Guo J, et al. Biogenic manganese oxides generated by green algae Desmodesmus sp. WR1 to improve bisphenol a removal. J Hazard Mater. 2017;339:310-9. https://doi.org/10.101 6/j.jhazmat.2017.06.026.

34. Sochacki A, Felis E, Bajkacz S, Kalka J, Michalska JK. Removal and transformation of benzotriazole in manganese-oxide biofilters with $\mathrm{Mn}(\mathrm{II})$ feeding. Chemosphere. 2018;212:143-51. https://doi.org/10.1016/j. chemosphere.2018.08.092

35. Dick GJ, Podell S, Johnson HA, Rivera-Espinoza Y, Bernier-Latmani R, McCarthy JK, et al. Genomic insights into Mn(II) oxidation by the marine alphaproteobacterium Aurantimonas sp. strain SI85-9A1. Appl Environ Microbiol. 2008;74:2646-58.

36. Wang $X$, Yu M, Wang L, Lin H, Li B, Xue CX, et al. Comparative genomic and metabolic analysis of manganese-oxidizing mechanisms in Celeribacter manganoxidans DY25T: its adaptation to the environment of polymetallic nodules. Genomics. 2020;112(2):2080-91. https://doi.org/10.1016/j.ygeno.201 9.12.002.

37. Meier-Kolthoff JP, Auch AF, Klenk HP, Göker M. Genome sequence-based species delimitation with confidence intervals and improved distance functions. BMC Bioinformatics. 2013;14(1):60. https://doi.org/10.1186/1471-21 05-14-60.

38. Goris J, Konstantinidis KT, Klappenbach JA, Coenye T, Vandamme P, Tiedje JM. DNA-DNA hybridization values and their relationship to whole-genome sequence similarities. Int J Syst Evol Microbiol. 2007;57:81-91.

39. Richter M, Rosselló-Móra R. Shifting the genomic gold standard for the prokaryotic species definition. Proc Natl Acad Sci U S A. 2009;106: 19126-31.

40. Richter M, Rosselló-Móra R, Oliver Glöckner F, Peplies J. JSpeciesWS: a web server for prokaryotic species circumscription based on pairwise genome comparison. Bioinformatics. 2016;32(6):929-31. https://doi.org/10.1093/ bioinformatics/btv681.

41. Ramana CV, Sasikala C, Arunasri K, Anil Kumar P, Srinivas TNR, Shivaji S, et al. Rubrivivax benzoatilyticus sp. nov., an aromatic hydrocarbondegradiing purple betaproteobacterium. Int J Syst Evol Microbiol. 2006; 56:2157-64.

42. Sheu SY, Li ZH, Young CC, Chen WM. Rubrivivax albus sp. nov., isolated from a freshwater pond. Int J Syst Evol Microbiol. 2020;70:805-13.

43. Nagashima S, Kamimura A, Shimizu T, Nakamura-Isaki S, Aono E, Sakamoto $\mathrm{K}$, et al. Complete genome sequence of phototrophic betaproteobacterium Rubrivivax gelatinosus IL 144. J Bacteriol. 2012;194:3541-2.

44. Vallenet D, Calteau A, Cruveiller S, Gachet M, Lajus A, Josso A, et al. MicroScope in 2017: an expanding and evolving integrated resource for community expertise of microbial genomes. Nucleic Acids Res. 2017;45: D517-28.

45. Miele V, Penel S, Duret L. Ultra-fast sequence clustering from similarity networks with SiLiX. BMC Bioinformatics. 2011;12:116.

46. Spiro TG, Bargar JR, Sposito G, Tebo BM. Bacteriogenic manganese oxides. Acc Chem Res. 2008;43:2-9.

47. Geszvain K, McCarthy JK, Tebo BM. Elimination of manganese(II, III) oxidation in Pseudomonas putida GB-1 by a double knockout of two putative multicopper oxidase genes. Appl Environ Microbiol. 2013;79:357-66. https:// doi.org/10.1128/AEM.01850-12.

48. Ridge JP, Lin M, Larsen El, Fegan M, Mcewan AG, Sly LI. A multicopper oxidase is essential for manganese oxidation and laccase-like activity in Pedomicrobium sp. ACM 3067. Environ Microbiol. 2007;9(4):944-53. https:// doi.org/10.1111/j.1462-2920.2006.01216.x.

49. Corstjens PLAM, Devrind JPM, Goosen T, de Vrind-de Jong EW. Identification and molecular analysis of the Leptothrix discophora SS-1 mofA gene, a gene putatively encoding a manganese-oxidizing protein with copper domains. Geomicrobiol J. 1997;14(2):91-108. https://doi.org/10.1080/01490459709378037.

50. Dick GJ, Torpey JW, Beveridge TJ, Tebo BM. Direct identification of a bacterial manganese(II) oxidase, the multicopper oxidase $M n \times G$, from spores of several different marine Bacillus species. Appl Environ Microbiol. 2008;74: 1527-34.

51. Geszvain K, Tebo BM. Identification of a two-component regulatory pathway essential for Mn(II) oxidation in Pseudomonas putida GB-1. App Environ Microbiol. 2010;76:1224-31.

52. Goldberg T, Hecht M, Hamp T, Karl T, Yachdav G, Ahmed N, et al. LocTree3 prediction of localization. Nucleic Acids Res. 2014;42:350-5. 
53. Geszvain K, Smesrud L, Tebo BM. Identification of a third Mn(II) oxidase enzyme in Pseudomonas putida GB-1. Appl Environ Microbiol. 2016;82(13): 3774-82. https://doi.org/10.1128/AEM.00046-16.

54. Anderson CR, Johnson HA, Caputo N, Davis RE, Torpey JW, Tebo BM. Mn(II) oxidation is catalyzed by heme peroxidases in Aurantimonas manganoxydans strain SI85-9A1 and Erythrobacter sp. strain SD-21. Appl Environ Microbiol. 2009;75:4130-8.

55. Brouwers GJ, Corstjens PLAM, De Vrind JPM, Verkamman A, De Kuyper M, De Vrind-De Jong EW. Stimulation of $\mathrm{Mn}^{2+}$ oxidation in Leptothrix discophora SS-1 by $\mathrm{Cu}^{2+}$ and sequence analysis of the region flanking the gene encoding putative multicopper oxidase MofA. Geomicrobiol J. 2000; 17:25-33.

56. Stincone A, Prigione A, Cramer T, Wmelink MM, Campbell K, Cheung E, et al. The return of metabolism: biochemistry and physiology of the pentose phosphate pathway. Biol Rev Camb Philos Soc. 2015;90(3):927-63. https:// doi.org/10.1111/brv.12140.

57. Ekici S, Pawlik G, Lohmeyer E, Koch HG, Daldal F. Biogenesis of cbb-type cytochrome $c$ oxidase in Rhodobacter capsulatus. Biochim Biophys Acta. 1817;2012(2):898-910. https://doi.org/10.1038/jid.2014.371.

58. Koch $\mathrm{HG}$, Hwang $\mathrm{O}$, Daldal F. Isolation and characterization of Rhodobacter capsulatus mutants affected in cytochrome $c b b_{3}$ oxidase activity. J Bacteriol. 1998;180:969-78.

59. Kulajta C, Thumfart JO, Haid S, Daldal F, Koch HG. Multi-step assembly pathway of the $c b b_{3}$-type cytochrome coxidase complex. J Mol Biol. 2006; 355:989-1004

60. Preisig O, Zufferey R, Hennecke $H$. The Bradyrhizobium japonicum fixGHIS genes are required for the formation of the high-affinity $c b b_{3}$-type cytochrome oxidase. Arch Microbiol. 1996;165(5):297-305. https://doi.org/1 $0.1007 / \mathrm{s} 002030050330$

61. Durand A, Bourbon ML, Steunou AS, Khalfaoui-Hassani B, Legrand C, Legrand $A$, et al. Biogenesis of the bacterial $c b b_{3}$ cytochrome $c$ oxidase: active subcomplexes support a sequential assembly model. J Biol Chem. 2018;293:808-18.

62. Atkinson MR, Ninfa AJ. Characterization of the GlnK protein of Escherichia coli. Mol Microbiol. 1999;32(2):301-13. https://doi.org/10.1046/j.1365-2958.1 999.01349.x

63. Blauwkamp TA, Ninfa AJ. Physiological role of the GlnK signal transduction protein of Escherichia coli: survival of nitrogen starvation. Mol Microbiol. 2002;46:203-14

64. Gosztolai A, Schumacher J, Behrends V, Bundy JG, Heydenreich F, Bennett $\mathrm{MH}$, et al. GInK facilitates the dynamic regulation of bacterial nitrogen assimilation. Biophys J. 2017;112:2219-30.

65. Magasanik B. Genetic control of nitrogen assimilation in bacteria. Annu Rev Genet. 1982;16:135-68.

66. Pahel G, Rothstein DM, Magasanik B. Complex glnA-glnL-glnG operon of Escherichia coli. J Bacteriol. 1982;150:202-13.

67. Schreier HJ, Sonenshein AL. Altered regulation of the glnA gene in glutamine synthetase mutants of Bacillus subtilis. J Bacteriol. 1986;167(1):3543. https://doi.org/10.1128/JB.167.1.35-43.1986.

68. He WH, Wang YN, Du X, Zhou Y, Jia B, Bian J, et al. Pseudomonas linyingensis sp. nov:: a novel bacterium isolated from wheat soil subjected to long-term herbicides application. Curr Microbiol. 2012;65:595-600.

69. Lin SY, Hameed A, Liu YC, Hsu YH, Lai WA, Chen WM, et al. Pseudomonas sagittaria sp. nov., a siderophore-producing bacterium isolated from oilcontaminated soil. Int J Syst Evol Microbiol. 2013;63:2410-7.

70. Mohan SB, Cole JA. The dissimilatory reduction of nitrate to ammonia by anaerobic bacteria. In: Bothe H, Ferguson SJ, Newton WE, editors. Biology of the Nitrogen Cycle. Elsevier B.V.; 2007. p. 93-106.

71. Kawasaki S, Arai H, Kodama T, Igarashi Y. Gene cluster for dissimilatory nitrite reductase (nir) from Pseudomonas aeruginosa: sequencing and identification of a locus for heme $d_{1}$ biosynthesis. J Bacteriol. 1997;179:235-42.

72. Ramos F, Blanco G, Gutiérrez JC, Luque F, Tortolero M. Identification of an operon involved in the assimilatory nitrate-reducing system of Azotobacter vinelandii. Mol Microbiol. 1993;8(6):1145-53. https://doi.org/10.1111/j.1365-2 958.1993.tb01659.x.

73. Yukioka Y, Tanahashi T, Shida K, Oguchi H, Ogawa S, Saito C, et al. A role of nitrite reductase (NirBD) for NO homeostatic regulation in Streptomyces coelicolor A3(2). FEMS Microbiol Lett. 2017;364:1-6.

74. Arcondéguy $T$, Jack R, Merrick M. Pll signal transduction proteins, pivotal players in microbial nitrogen control. Microbiol Mol Biol Rev. 2001;65:80-105.
75. Yurgel SN, Rice J, Mulder M, Kahn ML. GInB/GInK PIl proteins and regulation of the Sinorhizobium meliloti Rm1021 nitrogen stress response and symbiotic function. J Bacteriol. 2010;192(10):2473-81. https://doi.org/10.112 8/JB.01657-09.

76. Sant'Anna FH, Trentini DB, De Souto WS, Cecagno R, Da Silva SC, Schrank IS. The PII superfamily revised: a novel group and evolutionary insights. J Mol Evol. 2009;68:322-36.

77. Egener T, Martin DE, Sarkar A, Reinhold-Hurek B. Role of a ferredoxin gene cotranscribed with the nifHDK operon in $\mathrm{N}_{2}$ fixation and nitrogenase "switch-off" of Azoarcus sp. strain BH72. J Bacteriol. 2001;183:3752-60.

78. Martin AE, Burgess BK, lismaa SE, Smartt CT, Jacobson MR, Dean DR. Construction and characterization of an Azotobacter vinelandii strain with mutations in the genes encoding flavodoxin and ferredoxin I. J Bacteriol. 1989;171(6):3162-7. https://doi.org/10.1128/jb.171.6.3162-3167.1989.

79. Poudel S, Colman DR, Fixen KR, Ledbetter RN, Zheng Y, Pence N, et al. Electron transfer to nitrogenase in different genomic and metabolic backgrounds. J Bacteriol. 2018;200:1-19.

80. Yakunin AF, Gennaro G, Hallenbeck PC. Purification and properties of a nifspecific flavodoxin from the photosynthetic bacterium Rhodobacter capsulatus. J Bacteriol. 1993;175:6775-80.

81. Sirko A, Zatyka M, Sadowy E, Hulanicka D. Sulfate and thiosulfate transport in Escherichia coli K-12: evidence for a functional overlapping of sulfate- and thiosulfate-binding proteins. J Bacteriol. 1995;177(14):4134-6. https://doi. org/10.1128/JB.177.14.4134-4136.1995.

82. Loughlin P, Shelden MC, Tierney ML, Howitt SM. Structure and function of a model member of the SulP transporter family. Cell Biochem Biophys. 2002; 36(2-3):183-90. https://doi.org/10.1385/CBB:36:2-3:183.

83. Van De Kamp M, Pizzinini E, Vos A, Van Der Lende TR, Schuurs TA, Newbert RW, et al. Sulfate transport in Penicillium chrysogenum: cloning and characterization of the sutA and sutB genes. J Bacteriol. 1999;181:7228-34.

84. Parra F, Britton P, Castle C, Jones-Mortimer MC, Kornberg HL. Two separate genes involved in sulphate transport in Escherichia coli K12. J Gen Microbiol. 1983;129:357-8.

85. Rückert C, Koch DJ, Rey DA, Albersmeier A, Mormann S, Pühler A, et al. Functional genomics and expression analysis of the Corynebacterium glutamicum fpr2-cyclXHDNYZ gene cluster involved in assimilatory sulphate reduction. BMC Genomics. 2005;6:1-18.

86. Kushkevych I, Cejnar J, Treml J, Dordević D, Kollar P, Vítězová M. Recent advances in metabolic pathways of sulfate reduction in intestinal bacteria. Cells. 2020;9:698.

87. Bick JA, Dennis JJ, Zylstra GJ, Nowack J, Leustek T. Identification of a new class of 5'-adenylylsulfate (APS) reductases from sulfate-assimilating bacteria. J Bacteriol. 2000;182(1):135-42. https://doi.org/10.1128/JB.182.1.135-142.2000,

88. Abola AP, Willits MG, Wang RC, Long SR. Reduction of adenosine-5'phosphosulfate instead of 3'-phosphoadenosine- 5'-phosphosulfate in cysteine biosynthesis by Rhizobium meliloti and other members of the family Rhizobiaceae. J Bacteriol. 1999;181:5280-7.

89. Iwanicka-Nowicka R, Zielak A, Cook AM, Thomas MS, Hryniewicz MM. Regulation of sulfur assimilation pathways in Burkholderia cenocepacia: identification of transcription factors CysB and SsuR and their role in control of target genes. J Bacteriol. 2007;189:1675-88.

90. Rivera M. Bacterioferritin: structure, dynamics, and protein-protein interactions at play in iron storage and mobilization. Acc Chem Res. 2017. 50(2):331-40. https://doi.org/10.1021/acs.accounts.6b00514.

91. Tong Y, Guo M. Bacterial heme-transport proteins and their hemecoordination modes. Arch Biochem Biophys. 2009;481(1):1-15. https://doi. org/10.1016/j.abb.2008.10.013.

92. Liu R, Ochman H. Stepwise formation of the bacterial flagellar system. Proc Natl Acad Sci U S A. 2007;104:7116-21.

93. Yu Z, Chang M, Wu M, Yang G, Zhou S, Zhuang L. Pseudomonas oryzae sp. nov. isolated from a paddy soil in South China. Arch Microbiol. 2013;195(12): 815-22. https://doi.org/10.1007/s00203-013-0930-6.

94. Yang G, Han L, Wen J, Zhou S. Pseudomonas guangdongensis sp. nov., isolated from an electroactive biofilm, and emended description of the genus Pseudomonas Migula 1894. Int J Syst Evol Microbiol. 2013;63 PART 12: 4599-605.

95. Nogales J, García JL, Díaz E. Degradation of aromatic compounds in Pseudomonas: a systems biology view. In: Rojo F, editor. Aerobic utilization of hydrocarbons, oils and lipids. Handbook of hydrocarbon and lipid microbiology. Springer International Publishing AG; 2017. https://doi.org/1 0.1007/978-3-319-39782-5_32-1. 
96. de la Cruz AA, Hiskia A, Kaloudis T, Chernoff N, Hill D, Antoniou MG, et al. A review on cylindrospermopsin: the global occurrence, detection, toxicity and degradation of a potent cyanotoxin. Environ Sci Process Impacts. 2013; 15(11):1979-2003. https://doi.org/10.1039/c3em00353a.

97. Reva ON, Bezuidt O. Distribution of horizontally transferred heavy metal resistance operons in recent outbreak bacteria. Mob Genet Elements. 2012; 2:96-100.

98. Loux V, Mariadassou M, Almeida S, Chiapello H, Hammani A, Buratti J, et al. Mutations and genomic islands can explain the strain dependency of sugar utilization in 21 strains of Propionibacterium freudenreichii. BMC Genomics. 2015;16:1-19.

99. Zhu B, Zhang X, Zhao C, Chen S, Yang S. Comparative genome analysis of marine purple sulfur bacterium Marichromatium gracile YL28 reveals the diverse nitrogen cycle mechanisms and habitat-specific traits. Sci Rep. 2018; 8:1-11. https://doi.org/10.1038/s41598-018-36160-2.

100. Grindley NDF, Whiteson KL, Rice PA. Mechanisms of site-specific recombination. Annu Rev Biochem. 2006:75:567-605.

101. Martínez-García E, Jatsenko T, Kivisaar M, de Lorenzo V. Freeing Pseudomonas putida KT2440 of its proviral load strengthens endurance to environmental stresses. Environ Microbiol. 2014;17:76-90.

102. Dziewit L, Radlinska M. Two inducible prophages of an antarctic Pseudomonas sp. ANT_H14 use the same capsid for packaging their genomes - characterization of a novel phage helper-satellite system. PLoS One. 2016;11:1-27.

103. Paulsen IT, Press CM, Ravel J, Kobayashi DY, Myers GSA, Mavrodi DV, et al. Complete genome sequence of the plant commensal Pseudomonas fluorescens pf-5. Nat Biotechnol. 2005;23:873-8.

104. de Sousa LP. Mobile genetic elements in Pseudomonas stutzeri. Curr Microbiol. 2020;77:179-84. https://doi.org/10.1007/s00284-019-01812-7.

105. Couvin D, Bernheim A, Toffano-Nioche C, Touchon M, Michalik J, Néron B, et al. CRISPRCasFinder, an update of CRISRFinder, includes a portable version, enhanced performance and integrates search for Cas proteins. Nucleic Acids Res. 2018;46(W1):W246-51. https://doi.org/10.1093/nar/gky425.

106. Pourcel C, Touchon M, Villeriot N, Vernadet JP, Couvin D, Toffano-Nioche C, et al. CRISPRCasdb a successor of CRISPRdb containing CRISPR arrays and cas genes from complete genome sequences, and tools to download and query lists of repeats and spacers. Nucleic Acids Res. 2020;48:D535-44.

107. Makarova KS, Wolf YI, Iranzo J, Shmakov SA, Alkhnbashi OS, Brouns SJJ, et al. Evolutionary classification of CRISPR-Cas systems: a burst of class 2 and derived variants. Nat Rev Microbiol. 2020;18:67-83.

108. Bhaya D, Davison M, Barrangou R. CRISPR-Cas Systems in Bacteria and Archaea: versatile small RNAs for adaptive defense and regulation. Annu Rev Genet. 2011;45:273-97.

109. Nega M. Effects of micropollutants on the Panke River microbial communities and degradation of selected pharmaceuticals by manganeseoxidizing bacteria. Technische Universität Berlin; 2020. http://dx.doi.org/1 0.14279/depositonce-10452.

110. Wang G, Liu Y, Wu M, Zong W, Yi X, Zhan J, et al. Coupling the phenolic oxidation capacities of a bacterial consortium and in situ-generated manganese oxides in a moving bed biofilm reactor (MBBR). Water Res. 2019;166:115047. https://doi.org/10.1016/j.watres.2019.115047.

111. Tu J, Yang Z, Hu C, Qu J. Characterization and reactivity of biogenic manganese oxides for ciprofloxacin oxidation. J Environ Sci (China). 2014; 26(5):1154-61. https://doi.org/10.1016/S1001-0742(13)60505-7.

112. Liu Z, Wang J, Qian S, Wang G, Wang J, Liao S. Carbofuran degradation by biogenic manganese oxides. Bull Environ Contam Toxicol. 2017;98:420-5. https://doi.org/10.1007/s00128-016-1940-2

113. Wu Y, Shukal S, Mukherjee M, Cao B. Involvement in denitrification is beneficial to the biofilm lifestyle of Comamonas testosteroni: a mechanistic study and its environmental implications. Environ Sci Technol. 2015;49(19): 11551-9. https://doi.org/10.1021/acs.est.5b03381.

114. Burgin AJ, Hamilton SK, Gardner WS, McCarthy MJ. Nitrate reduction, denitrification, and dissimilatory nitrate reduction to ammonium in wetland sediments; 2015. p. 519-37.

115. Wang S, Pi Y, Song Y, Jiang Y, Zhou L, Liu W, et al. Hotspot of dissimilatory nitrate reduction to ammonium (DNRA) process in freshwater sediments of riparian zones. Water Res. 2020;173:115539. https://doi.org/10.1016/j.watres.2020.115539.

116. Li X, Song C, Zhou Z, Xiao J, Wang S, Yang L, et al. Comparison of community and function of dissimilatory nitrate reduction to ammonium (DNRA) bacteria in Chinese Shallow Lakes with different eutrophication degrees. Water (Switzerland). 2020;12:1-15.
117. Atlas R. Handbook of microbiological media, fourth edition. Fourth edi. Washington, D. C: Taylor \& Francis Group, LLC; 2010. https://doi.org/10.1201/ EBK1439804063.

118. Parks DH, Imelfort M, Skennerton CT, Hugenholtz P, Tyson GW. CheckM: assessing the quality of microbial genomes recovered from isolates, single cells, and metagenomes. Genome Res. 2015;25:1043-55.

119. Vallenet D, Belda E, Calteau A, Cruveiller S, Engelen S, Lajus A, et al. MicroScope - an integrated microbial resource for the curation and comparative analysis of genomic and metabolic data. Nucleic Acids Res. 2013;41(D1):D636-47. https://doi.org/10.1093/nar/gks1194.

120. Tatusov RL. The COG database: a tool for genome-scale analysis of protein functions and evolution. Nucleic Acids Res. 2000;28:33-6.

121. Kanehisa M, Sato Y, Morishima K. BlastKOALA and GhostKOALA: KEGG tools for functional characterization of genome and metagenome sequences. J Mol Biol. 2016:428:726-31. https://doi.org/10.1016/j.jmb.2015.11.006.

122. Caspi R, Billington R, Fulcher CA, Keseler IM, Kothari A, Krummenacker M, et al. The MetaCyc database of metabolic pathways and enzymes. Nucleic Acids Res. 2018;46(D1):D633-9. https://doi.org/10.1093/nar/gkx935.

123. Chaumeil P-A, Mussig AJ, Hugenholtz P, Parks DH. GTDB-Tk: a toolkit to classify genomes with the genome taxonomy database. Bioinformatics. 2019;36:1925-7.

124. Parks DH, Chuvochina M, Waite DW, Rinke C, Skarshewski A, Chaumeil PA, et al. A standardized bacterial taxonomy based on genome phylogeny substantially revises the tree of life. Nat Biotechnol. 2018;36(10):996-1004. https://doi.org/10.1038/nbt.4229.

125. Meier-Kolthoff JP, Göker M. TYGS is an automated high-throughput platform for state-of-the-art genome-based taxonomy. Nat Commun. 2019;10. https://doi.org/10.1038/s41467-019-10210-3.

126. Ondov BD, Treangen TJ, Melsted P, Mallonee AB, Bergman NH, Koren S, et al. Mash: fast genome and metagenome distance estimation using MinHash. Genome Biol. 2016;17:1-14. https://doi.org/10.1186/s13059-0160997-x.

127. Lagesen K, Hallin P, Rødland EA, Stærfeldt HH, Rognes T, Ussery DW. RNAmmer: consistent and rapid annotation of ribosomal RNA genes. Nucleic Acids Res. 2007;35:3100-8.

128. Camacho C, Coulouris G, Avagyan V, Ma N, Papadopoulos J, Bealer K, et al. BLAST+: architecture and applications. BMC Bioinformatics. 2009;10:1-9.

129. Lefort V, Desper R, Gascuel O. FastME 2.0: a comprehensive, accurate, and fast distance-based phylogeny inference program. Mol Biol Evol. 2015;32: 2798-800.

130. Kurtz S, Phillippy A, Delcher AL, Smoot M, Shumway M, Antonescu C, et al. Versatile and open software for comparing large genomes. Genome Biol. 2004;5(2):R12. https://doi.org/10.1186/gb-2004-5-2-r12.

131. Teeling H, Meyerdierks A, Bauer M, Amann R, Glöckner FO. Application of tetranucleotide frequencies for the assignment of genomic fragments. Environ Microbiol. 2004;6:938-47.

132. Vallenet D, Calteau A, Dubois M, Amours P, Bazin A, Beuvin M, et al. MicroScope: an integrated platform for the annotation and exploration of microbial gene functions through genomic, pangenomic and metabolic comparative analysis. Nucleic Acids Res. 2020;48:D579-89.

133. Mitchell AL, Attwood TK, Babbitt PC, Blum M, Bork P, Bridge A, et al. InterPro in 2019: improving coverage, classification and access to protein sequence annotations. Nucleic Acids Res. 2019;47(D1):D351-60. https://doi.org/10.1 093/nar/gky1100.

134. Francis CA, Tebo BM. Enzymatic manganese(II) oxidation by metabolically dormant spores of diverse Bacillus species. Appl Environ Microbiol. 2002;68: 874-80

135. Tang W, Liu Y, Gong J, Chen S, Zeng X. Analysis of manganese oxidase and its encoding gene in Lysinibacillus strain MK-1. Process Saf Environ Prot. 2019;127:299-305. https://doi.org/10.1016/j.psep.2019.04.002.

136. Edgar RC. MUSCLE: multiple sequence alignment with high accuracy and high throughput. Nucleic Acids Res. 2004;32(5):1792-7. https://doi.org/10.1 093/nar/gkh340

137. Solovyev $V$, Salamov A. Automatic annotation of microbial genomes and metagenomic sequences. In: Li RW, editor. Metagenomics and its applications in agriculture, biomedicine and environmental studies: Nova Science Publishers; 2011. p. 61-78. https://www.researchgate.net/publica tion/259450599_V_Solovyev_A_Salamov_2011_Automatic_Annotation_of Microbial_Genomes_and_Metagenomic_Sequences_In_Metagenomics_a nd its Applications in Agriculture Biomedicine and Environmental Studies_Ed_RW_Li_Nova_Sc. 
138. Blin K, Shaw S, Steinke K, Villebro R, Ziemert N, Lee SY, et al. AntiSMASH 5.0: updates to the secondary metabolite genome mining pipeline. Nucleic Acids Res. 2019;47(W1):W81-7. https://doi.org/10.1093/nar/gkz310.

139. Schalk IJ, Rigouin C, Godet J. An overview of siderophore biosynthesis among fluorescent pseudomonads and new insights into their complex cellular organization. Environ Microbiol. 2020;22:1447-66.

140. Crosa JH, Walsh CT. Genetics and assembly line enzymology of siderophore biosynthesis in bacteria. Microbiol Mol Biol Rev. 2002;66(2):223-49. https:// doi.org/10.1128/MMBR.66.2.223-249.2002.

141. Khan A, Singh P, Srivastava A. Synthesis, nature and utility of universal iron chelator - Siderophore: a review. Microbiol Res. 2018;212-213:103-11. https://doi.org/10.1016/j.micres.2017.10.012.

142. Visser MB, Majumdar S, Hani E, Sokol PA. Importance of the ornibactin and pyochelin siderophore transport systems in Burkholderia cenocepacia lung infections. Infect Immun. 2004:72:2850-7.

143. Hsiao W, Wan I, Jones SJ, Brinkman FSL. IslandPath: aiding detection of genomic islands in prokaryotes. Bioinformatics. 2003;19:418-20.

144. Waack S, Keller O, Asper R, Brodag T, Damm C, Fricke WF, et al. Score-based prediction of genomic islands in prokaryotic genomes using hidden Markov models. BMC Bioinformatics. 2006;7:1-12.

145. Bertelli C, Laird MR, Williams KP, Lau BY, Hoad G, Winsor GL, et al. IslandViewer 4: expanded prediction of genomic islands for larger-scale datasets. Nucleic Acids Res. 2017;45:W30-5.

146. Langille MGl, Hsiao WWL, Brinkman FSL. Evaluation of genomic island predictors using a comparative genomics approach. BMC Bioinformatics. 2008:9:1-10.

147. Arndt D, Grant JR, Marcu A, Sajed T, Pon A, Liang Y, et al. PHASTER: a better, faster version of the PHAST phage search tool. Nucleic Acids Res. 2016; 44(W1):W16-21. https://doi.org/10.1093/nar/gkw387.

148. Ecale Zhou CL, Malfatti S, Kimbrel J, Philipson C, McNair K, Hamilton T, et al. multiPhATE: bioinformatics pipeline for functional annotation of phage isolates. Bioinformatics. 2019;35:4402-4.

149. Mcnair K, Zhou C, Dinsdale EA, Souza B, Edwards RA, Hancock J. PHANOTATE: a novel approach to gene identification in phage genomes. Bioinformatics. 2019; 35(22):4537-42. https://doi.org/10.1093/bioinformatics/btz265.

150. Grazziotin AL, Koonin EV, Kristensen DM. Prokaryotic virus orthologous groups (pVOGs): a resource for comparative genomics and protein family annotation. Nucleic Acids Res. 2017;45:D491-8.

151. Bairoch A, Apweiler R. The SWISS-PROT protein sequence database and its supplement TrEMBL in 2000. Nucleic Acids Res. 2000;28:45-8.

152. Seguritan V, Alves N, Arnoult M, Raymond A, Lorimer D, Burgin AB, et al. Artificial neural networks trained to detect viral and phage structural proteins. PLoS Comput Biol. 2012;8:e1002657.

153. Galiez C, Magnan CN, Coste F, Baldi P. VIRALpro: a tool to identify viral capsid and tail sequences. Bioinformatics. 2016;32(9):1405-7. https://doi. org/10.1093/bioinformatics/btv727.

154. Nishimura Y, Yoshida T, Kuronishi M, Uehara H, Ogata H, Goto S. ViPTree: the viral proteomic tree server. Bioinformatics. 2017;33:2379-80.

155. Kolde R. pheatmap: Pretty heatmaps. R package version 1.0.8; 2015.

156. Chen $\mathrm{H}$, Boutros $\mathrm{PC}$. VennDiagram: a package for the generation of highlycustomizable Venn and Euler diagrams in R. BMC Bioinformatics. 2011;12:35.

157. Wilkins D. gggenes: Draw gene arrow maps in "ggplot2." R package version 0.4.0. 2019. https://cran.r-project.org/package=gggenes.

158. Garnier S. viridis: Default color maps from "matplotlib". R package version 0. 5.1. 2018. https://cran.r-project.org/package=viridis.

159. Neuwirth E. RColorBrewer: ColorBrewer palettes. R package version 1.1-2. 2014. https://cran.r-project.org/package=RColorBrewer.

160. R Core Team. R: A language and environment for statistical computing. 2020. https://www.r-project.org/.

161. R Core Team. RStudio: Integrated development for R. v1.0.153. 2016. http:// www.rstudio.com/

162. Letunic I, Bork P. Interactive tree of life (iTOL) v4: recent updates and new developments. Nucleic Acids Res. 2019;47:256-9.

163. Farris JS. Estimating phylogenetic trees from distance matrices. Am Nat. 1972;106(951):645-68. https://doi.org/10.1086/282802

\section{Publisher's Note}

Springer Nature remains neutral with regard to jurisdictional claims in published maps and institutional affiliations.

\section{Ready to submit your research? Choose BMC and benefit from:}

- fast, convenient online submission

- thorough peer review by experienced researchers in your field

- rapid publication on acceptance

- support for research data, including large and complex data types

- gold Open Access which fosters wider collaboration and increased citations

- maximum visibility for your research: over $100 \mathrm{M}$ website views per year

At BMC, research is always in progress.

Learn more biomedcentral.com/submissions 